\title{
Treatment with Thyroxine Restores Myelination and Clinical Recovery after Intraventricular Hemorrhage
}

\author{
Linnea R. Vose, ${ }^{1}$ Govindaiah Vinukonda, ${ }^{1,2}$ Sungro Jo, ${ }^{5}$ Omid Miry, ${ }^{2}$ Daniel Diamond, ${ }^{2}$ Ritesh Korumilli, ${ }^{1}$ \\ Arslan Arshad, ${ }^{1}$ Muhammad T. K. Zia, ${ }^{1}$ Furong Hu, ${ }^{1}$ Robert J. Kayton, ${ }^{3}$ Edmund F. La Gamma, ${ }^{1}$ ashmi Bansal, ${ }^{4}$ \\ Antonio C. Bianco, ${ }^{5}$ and Praveen Ballabh ${ }^{1,2}$ \\ Departments of ${ }^{1}$ Pediatrics, and ${ }^{2}$ Cell Biology and Anatomy, Regional Neonatal Center, Maria Fareri Children's Hospital at Westchester Medical Center- \\ New York Medical College, Valhalla, New York 10595, ${ }^{3}$ Department of Physiology and Pharmacology, Oregon Health \& Science University, Portland, Oregon \\ 97239, ${ }^{4}$ Department of Neuroscience, University of Connecticut, Farmington, Connecticut 06269, and ${ }^{5}$ Division of Endocrinology, Diabetes and \\ Metabolism, University of Miami Miller School of Medicine, Miami, Florida 33146
}

Intraventricular hemorrhage (IVH) remains a major cause of white matter injury in preterm infants with no viable therapeutic strategy to restore myelination. Maturation of oligodendrocytes and myelination is influenced by thyroid hormone $(\mathrm{TH})$ signaling, which is mediated by TH receptor $\alpha$ (TR $\alpha)$ and TR $\beta$. In the brain, cellular levels of TH are regulated by deiodinases, with deiodinase- 2 mediating TH activation and deiodinase- 3 TH inactivation. Therefore, we hypothesized that IVH would decrease TH signaling via changes in the expression of deiodinases and/or TRs, and normalization of TH signaling would enhance maturation of oligodendrocytes and myelination in preterm infants with IVH. These hypotheses were tested using both autopsy materials from human preterm infants and a rabbit model of IVH. We found that deiodinase-2 levels were reduced, whereas deiodinase-3 levels were increased in brain samples of both humans and rabbits with IVH compared with controls without IVH. TR $\alpha$ expression was also increased in human infants with IVH. Importantly, treatment with TH accelerated the proliferation and maturation of oligodendrocytes, increased transcription of Olig2 and Sox10 genes, augmented myelination, and restored neurological function in pups with IVH. Consistent with these findings, the density of myelinating oligodendrocytes was almost doubled in TH-treated human preterm infants compared with controls. Thus, in infants with IVH the combined elevation in deiodinase- 3 and reduction in deiodinase- 2 decreases TH signaling that can be worsened by an increase in unliganded TR $\alpha$. Given that TH promotes neurological recovery in IVH, TH treatment might improve the neurodevelopmental outcome of preterm infants with IVH.

\section{Introduction}

Intraventricular hemorrhage (IVH) is the most common neurological disorder of preterm infants and remains a major cause of white matter injury in this population. No therapeutic strategy exists to prevent hypomyelination and consequent neurological disabilities induced by IVH among the survivors. Thyroid hormone $(\mathrm{TH})$ plays a distinct role in white matter development (Bernal, 2007). It orchestrates the maturation of oligodendrocytes (OLs) and formation of myelinated axons. Herein, we asked whether IVH would increase cellular degradation of TH in the brain and whether TH supplementation could enhance myelination in preterm newborns with hemorrhage, and determined

\footnotetext{
Received June 25, 2013; revised Aug. 30, 2013; accepted Sept. 17, 2013.

Author contributions: L.R.V., R.B., E.F.L.G., and P.B. designed research; L.R.V., G.V., S.J., O.M., D.D., R.K., A.A., M.T.K.Z., F.H., and R.J.K. performed research; R.B. contributed unpublished reagents/analytic tools; L.R.V. and S.J. analyzed data; L.R.V., A.C.B., and P.B. wrote the paper.

This work was supported by National Institutes of Health-National Institute of Neurological Disorders and Stroke Grant R01 NS071263 (P.B.) and a Scientist Development Grant from the American Heart Association (G.V.). We thank Joanne Abrahams for the assistance with images.

The authors declare no competing financial interests.

Correspondence should be addressed to Dr. Praveen Ballabh, Regional Neonatal Center, Maria Fareri Children's Hospital at Westchester Medical Center, Valhalla, NY 10595. E-mail: Pballabh@msn.com.

DOI:10.1523/JNEUROSCI.2713-13.2013

Copyright $\odot 2013$ the authors $\quad 0270-6474 / 13 / 3317232-15 \$ 15.00 / 0$
}

the molecular basis of neurological recovery after $\mathrm{TH}$ treatment of IVH.

Thyroxine $\left(\mathrm{T}_{4}\right)$ is a prohormone that must be deiodinated to triiodothyronine $\left(\mathrm{T}_{3}\right)$, the active form of $\mathrm{TH}$, to bind to nuclear $\mathrm{TH}$ receptors (TRs; Bernal, 2007). Ligand binding alters TR conformation to recruit coactivator complexes, thereby regulating target gene expression (Bernal, 2007). Conversely, unliganded TRs recruit corepressor complexes to inhibit target gene transcription. During the development of OLs, TH signaling in OL progenitors promotes OL specification and differentiation (Carré et al., 1998; Rodríguez-Peña, 1999). Indeed, hypothyroidism causes hypomyelination, while TH treatment promotes myelination in animal models of adult demyelination (Fernandez et al., 2004b; Harsan et al., 2008). Intracellular availability of $\mathrm{T}_{3}$ is critically modulated by two deiodinases: the activating type-2 deiodinase (D2), largely expressed in astrocytes, and the inactivating type-3 deiodinase (D3), present in neurons (Courtin et al., 2005; Gereben et al., 2008). D2 activates $T_{4}$ to $T_{3}$, while D3 inactivates both $\mathrm{T}_{3}$ and $\mathrm{T}_{4}$. About half of the $\mathrm{T}_{3}$ content in the brain is locally generated by D2 (Bernal, 2007); thus, deiodinasedependent mechanisms play an important role in regulating gene transcription and consequent metabolism, proliferation, and maturation of OLs.

The onset of IVH triggers oxidative stress and inflammation in the adjacent periventricular white matter, resulting in degenera- 
tion, reduced proliferation, and arrested maturation of cells in the OL lineage (Dummula et al., 2011). Oxidative stress enhances D3 activity and suppresses D2 activity in cultured astrocytes (Lamirand et al., 2008). Similarly, hypoxia-ischemia in rats induces D3 in hippocampal neurons (Jo et al., 2012), and transient focal cerebral ischemia elevates D2 gene expression in astrocytes of rat striatum and cerebral cortex (Margaill et al., 2005). Hence, reactive oxygen species generated by IVH might reduce $\mathrm{T}_{3}$ concentration in neural cells by activating D3 and inhibiting D2. Moreover, gestational hypoxia and ischemia in separate experiments increases gene expression of TR $\alpha$ (Royer et al., 2000; Zhu et al., 2004). Despite this, deiodinase levels, expression of TRs, or the effect of treatment with $\mathrm{TH}$ on cerebral myelination has not been evaluated in the brain of premature newborns with IVH. Therefore, we hypothesized that the development of IVH would induce distinct changes in the expression of cellular deiodinases and TRs, and that treatment with TH might enhance myelination and neurological recovery in preterm newborns with IVH. We also postulated that treatment with $\mathrm{TH}$ would enhance the transcription of genes promoting myelination, and induce proliferation and maturation of OL progenitors.

\section{Materials and Methods}

Animals. The study was approved by the Institutional Animal Care and Use Committee of New York Medical College. We used a rabbit model of glycerol-induced IVH in the study. The details of the model have been previously established and published (Chua et al., 2009). Briefly, we obtained timed-pregnant New Zealand rabbits from Charles River Laboratories. We performed a cesarean section to deliver the pups prematurely at embryonic day (E) E29 (full-term, E32). Newborn pups were kept in an infant incubator prewarmed to a temperature of $35^{\circ} \mathrm{C}$. The pups were gavage-fed puppy formula (Esbilac), $\sim 2 \mathrm{ml}$ every $12 \mathrm{~h}(100 \mathrm{ml} / \mathrm{kg} / \mathrm{d}$ ) for the first $2 \mathrm{~d}$, and feeds were advanced to $125,150,200,250$, and $280 \mathrm{ml} / \mathrm{kg}$ at postnatal days $3,5,7,10$, and 14, respectively. Rabbit pups of either sex were administered $50 \%$ glycerol $(6.5 \mathrm{~g} / \mathrm{kg}$, i.p.) at $2 \mathrm{~h}$ of age to induce IVH. The severity of IVH was diagnosed by measuring ventricle volume (length, breadth, and depth in coronal and sagittal views) on head ultrasound at $24 \mathrm{~h}$ of age using an Acuson Sequoia C256 (Siemens) ultrasound machine. Pups were classified based on ventricular volume into moderate $\left(30-150 \mathrm{~mm}^{3}\right)$ and severe $\left(151-250 \mathrm{~mm}^{3}\right)$ IVH. Ventricular volume of $<30 \mathrm{~mm}^{3}$ indicates microscopic or no IVH. The pups with moderate and severe IVH were alternately assigned to treatment and control groups so that the severity of IVH was balanced between the comparison groups.

Thryoxine treatment. Rabbit pups with IVH were sequentially treated with either thyroxine ( $20 \mu \mathrm{g} / \mathrm{kg}$ once daily; Sigma) or vehicle intramuscularly for $10 \mathrm{~d}$ starting at $24 \mathrm{~h}$ age. The severity of IVH, measured by ultrasound, was similar between the comparison groups-thyroxinetreated and vehicle-treated pups with IVH. The pups killed at 3 and $7 \mathrm{~d}$ received intramuscular thyroxine until the day they were killed. Healthy pups were treated with thyroxine in the same manner as above.

Human subjects. The Research Administration of New York Medical College approved the use of autopsy materials from premature infants for this study. The study materials included forebrain tissue samples taken from premature infants with and without IVH of 23-27 gestational weeks (gw) of age and $<5 \mathrm{~d}$ of postnatal age (Table 1 ). Samples were obtained $<18 \mathrm{~h}$ postmortem. We excluded premature infants with meningitis, hypoxic-ischemic encephalopathy, culture-proven sepsis, major brain or spinal cord malformation, and chromosomal defects. We included nine infants in each group-IVH and no IVH. The wall of the cerebral hemisphere in premature infants comprises ventricular zone, subventricular zone, intermediate zone, cortical plate, and marginal zone as described by the Boulder Committee (Bystron et al., 2008). In the present study, we described intermediate-zone embryonic white matter synonymously with white matter and cerebral cortex for the cortical plate.

We also included a set of three preterm infants $(25,25$, and $24 \mathrm{gw})$, who were enrolled in a double-blinded randomized trial for $\mathrm{T}_{4}$ treatment
Table 1. Characteristics of human infants with and without IVH

\begin{tabular}{lllll}
\hline $\begin{array}{l}\text { Postconceptional } \\
\text { age (weeks) }\end{array}$ & Sex & $\begin{array}{l}\text { Birth } \\
\text { weight } \\
(\mathrm{kg})\end{array}$ & IVH/no IVH & Cause of death \\
\hline 27 & Male & 0.80 & Grade 3 IVH & Clinical sepsis \\
24 & Male & 0.64 & Grade 4 IVH & Pulmonary hemorrhage \\
24 & Female & 0.60 & Grade 3 IVH & RDS, respiratory failure \\
23 & Male & 0.57 & Grade 2 IVH & Clinical sepsis \\
23 & Female & 0.58 & Grade 3 IVH & Respiratory failure \\
23 & Male & 0.51 & Grade 2 IVH & Respiratory failure \\
25 & Male & 0.74 & Grade 4 IVH & Metabolic acidosis, respiratory failure \\
24 & Male & 0.64 & Grade 3 IVH & Clinical sepsis \\
24 & Male & & Grade 2 IVH & Clinical sepsis \\
27 & Female & 0.56 & No IVH & Respiratory failure \\
26 & Female & 0.92 & No IVH & Clinical sepsis \\
24 & Male & 0.61 & No IVH & Clinical sepsis \\
24 & Male & 0.73 & No IVH & Metabolic acidosis, respiratory failure \\
23 & Male & 0.45 & No IVH & RDS, respiratory failure \\
22 & Female & 0.50 & No IVH & RDS, respiratory failure \\
22 & Female & 0.55 & No IVH & RDS, respiratory failure \\
23 & Male & 0.54 & No IVH & RDS, respiratory failure \\
23 & Male & 0.61 & No IVH & RDS, respiratory failure \\
\hline
\end{tabular}

RDS, Respiratory distress syndrome.

and died at postnatal days 27,30, and 7, respectively (Table 2; La Gamma et al., 2009). To compare these $\mathrm{T}_{4}$-treated infants with untreated controls, autopsy samples from three other preterm infants, who were matched for both gestational and postnatal age, were evaluated. The $\mathrm{T}_{4}$ treatment ( 4 or $8 \mu \mathrm{g} / \mathrm{kg} / \mathrm{d}$ ) was initiated at day 1 and was continued until the day of demise.

Rabbit tissue collection and processing. We processed the tissues as described previously (Ballabh et al., 2007). Coronal brain slices were fixed in $4 \%$ paraformaldehyde in $0.1 \mathrm{M}$ PBS, $\mathrm{pH} 7.4$, overnight and then were cryoprotected by immersing into $20 \%$ sucrose in $0.1 \mathrm{M}$ PBS buffer for $24 \mathrm{~h}$ followed by $30 \%$ sucrose for the next $24 \mathrm{~h}$. We next froze the tissues after embedding into optimum cutting temperature compound. Frozen blocks were cut on a cryostat into coronal sections of $20 \mu \mathrm{m}$ thickness. For Western blot analyses, a 1- to 2-mm-thick coronal slice was harvested at the level of the midseptal nucleus and snap frozen on dry ice.

Human tissue collection and processing. We processed the tissues as in our previous studies (Ballabh et al., 2007). Approximately 3- to 4-mmthick coronal slices were taken at the level of the head of the caudate nucleus from the frontoparietal lobe. The coronal blocks consisted of cortex, white matter, and germinal matrix. The samples were immersion fixed in 4\% paraformaldehyde in PBS for 12-18 $\mathrm{h}$ and were then cryoprotected by immersion into a $20 \%$ sucrose solution in PBS, followed by $30 \%$ sucrose in PBS. The tissues were frozen after embedding them into an optimum-cutting-temperature compound (Sakura, Tokyo, Japan). Frozen coronal blocks were cut into sections of $20 \mu \mathrm{m}$ thickness. For Western blot analyses, pieces of tissue were directly harvested from the cortex, white matter, and germinal matrix, and snap frozen on dry ice.

Immunohistochemistry. Immunostaining was performed as described previously (Ballabh et al., 2007). The primary antibodies used in these experiments included the following: mouse monoclonal TR $\alpha$ (catalog \#PP-H2804-00, Perseus Proteomics); rabbit polyclonal TR $\beta$ (catalog \#NB100-91999, Novus); goat polyclonal deiodinase-2 (catalog \#NBP100178, Novus); rabbit polyclonal deiodinase-3 (catalog \#NBP1-05767, Novus); mouse monoclonal mitogen-activated protein 2 (MAP2; catalog \#9942 Sigma); goat polyclonal Olig2 (catalog \#AF-2418, R\&D Systems); mouse monoclonal GFAP (catalog \#G6171, Sigma); rat monoclonal myelin basic protein (MBP; catalog \#AB7439, Abcam); mouse monoclonal myelin-associated glycoprotein (MAG; catalog \#AB89780, Abcam); mouse monoclonal 2',3'-cyclic-nucleotide $3^{\prime}$-phosphodiesterase (CNPase; catalog \#SMI-91, Covance); goat polyclonal PDGF receptor $\alpha$ (PDGFR $\alpha$; catalog \#AR307, R\&D Systems); mouse monoclonal Adenomatus Polyposis Coli, CC1 clone (catalog \#OP80, EMD Chemicals); goat polyclonal Ki67 (catalog \#275R-14, Cell Marque); and mouse monoclonal caspase 3 (clone \#3CSP01, Thermo Scientific). Biotinylated O4 
Table 2. Premature infants treated with thyroid hormone and their matched controls

\begin{tabular}{|c|c|c|c|c|c|c|}
\hline Gestational age (weeks) & Postnatal age (d) & Sex & Birth weight $(\mathrm{kg})$ & IVH/no IVH & Dose of thyroxine & Cause of death \\
\hline \multicolumn{7}{|l|}{ Thyroxine treated infants } \\
\hline 25 & 27 & Male & 0.68 & Grade 1 IVH & $4 \mu \mathrm{g} / \mathrm{kg} / \mathrm{d}$ & Necrotizing enterocolitis \\
\hline 25 & 30 & Female & 0.80 & Grade 3 IVH & $4 \mu \mathrm{g} / \mathrm{kg} / \mathrm{d}$ & Endocarditis, Clinical sepsis \\
\hline 24 & 7 & Male & 0.63 & Grade 1 IVH & $8 \mu \mathrm{g} / \mathrm{kg} / \mathrm{d}$ & Clinical sepsis \\
\hline \multicolumn{7}{|c|}{ Untreated matched controls } \\
\hline 25 & 27 & Male & 0.77 & Grade 3-4 IVH & & Necrotizing enterocolitis \\
\hline 24 & 29 & Female & 0.55 & Grade 1 IVH & & Pneumothorax, clinical sepsis \\
\hline 24 & 4 & Male & 0.65 & Grade 2 IVH & & Respiratory failure \\
\hline
\end{tabular}

Thyroxine treatment was initiated at day 1 in the treated infants and continued until demise.

monoclonal and O1 monoclonal antibody was provided by Dr. Rashmi Bansal (University of Connecticut, Storrs, CT). Secondary antibodies used were $\mathrm{Cy}-3$ conjugate donkey anti-mouse, $\mathrm{Cy}-3$ conjugate donkey anti-goat, and FITC-conjugated donkey anti-rat (Jackson Immuno Research). Briefly, we hydrated the fixed sections in $0.01 \mathrm{~m}$ PBS, blocked the sections with normal donkey serum in PBS with $0.01 \%$ Triton X-100 (PBST), and incubated with the primary antibodies diluted in PBST at $4^{\circ} \mathrm{C}$ overnight. After several washes in PBS, the sections were incubated with secondary antibody diluted in $1 \%$ normal goat serum in PBS at room temperature for $60 \mathrm{~min}$. Finally, after washing in PBS, sections were mounted with Slow Fade Light Antifade reagent (Invitrogen) and were visualized under a confocal microscope (Nikon Instruments). Stereology was performed using a fluorescent microscope (Axioskop 2 plus, Carl Zeiss) with motorized specimen stage for automated sampling (ASI), CCD color video camera (Microfire, Optronics), and stereology software (Stereologer, SRC).

Fluorescent in situ detection of DNA fragmentation (TUNEL). We performed TUNEL staining on fixed brain sections as described previously (Dummula et al., 2011). For TUNEL staining, tissue sections of $15 \mu \mathrm{m}$ thickness were air dried on slides, hydrated in $0.01 \mathrm{M}$ PBS, and permeabilized for $5 \mathrm{~min}$ in 1:1 ethanol/acetic acid. An ApopTag-fluorescein in situ DNA fragmentation detection kit (catalog \#S7110; Millipore) was used to visualize TUNEL-labeled nuclei.

Quantification of oligodendrocytes. Proliferation and maturation of OLs were evaluated in the corona radiata and corpus collosum of pups without IVH and pups with IVH treated with vehicle or $\mathrm{T}_{4}$. Proliferating OL progenitors were identified by double labeling the coronal sections with Olig2 and Ki67 antibodies, while maturation of OL progenitors was assessed by double labeling the sections with $\mathrm{O} 4$ and APC antibodies. All immunolabeled sections were obtained from the level of the midseptal nucleus (five $20 \mu \mathrm{m}$ sections, $60 \mu \mathrm{m}$ between each). Quantification was performed by a blinded investigator in a random, unbiased fashion using a confocal microscope with a $60 \times$ lens (Nikon Instruments). Cells were counted in $\sim 25$ images ( 5 images $\times 5$ sections) for each brain region, for every parameter, and for each pup ( $n=5$ pups per group).

Stereological assessment of myelin and astrocytes in the white matter. Unbiased stereology methods, with assistance from a computerized software system (Stereologer, Stereology Resource Center), were used to quantify a number of parameters. Briefly, coronal sections of $20 \mu \mathrm{m}$ thickness were cut on a cryostat with a section sampling interval of $90 \mu \mathrm{m}$ to achieve six sections or more at the level of mid-septal nucleus. The sections were double labeled with MBP antibody and DAPI (nuclear stain), and quantified as follows. The reference spaces (corona radiata, corpus callosum) were first outlined on the section under $5 \times$ objective. The volume of the outlined area (reference space) was quantified using a point-counting probe (frame, $25 \times 25 \mu \mathrm{m}$; guard zone, $2 \mu \mathrm{m}$; interframe interval, $300 \mu \mathrm{m}$ ). The total volume fraction (load) of myelin stained by antibodies to MBP through a defined reference space was estimated using the object area fraction probe under $60 \times$ oil lens. For the area fraction probe (frame, $25 \times 25 \mu \mathrm{m}$; guard zone, $2 \mu \mathrm{m}$; interframe interval, 400 $\mu \mathrm{m}$ ), the user clicked on the grid points that overlapped the myelin fibers in sections labeled with MBP. The area fraction of myelination was quantified as the ratio of product of the area per point and number of points hitting reference area the over the product of the area per point and number of points hitting the sampled area $\left[a\right.$ (point) $\left.\cdot \Sigma P_{\text {samp }}\right]$, as reported previously. A coefficient of error $<0.10$ was acceptable. To assess gliosis, we estimated the total volume fraction of astrocyte cell body and glial fibers (Mouton et al., 2009). The volume fraction of astrocytes was quantified in a similar manner as for myelin.

Western blot analyses. We homogenized the frozen brain tissue in sample buffer (3\% SDS, 10\% glycerol, and $62.5 \mathrm{~mm}$ Tris- $\mathrm{HCl}$ ) using a mechanical homogenizer and briefly sonicated the lysate before centrifugation. Supernatant protein concentration was determined using a BCA protein assay kit (Pierce Kit \#23227, Thermo Scientific) with BSA to create the standard curve. After boiling the samples in Laemmli buffer (catalog \#161-0737, Bio-Rad), total protein samples were separated by SDS-PAGE (Ballabh et al., 2007). Equal amounts of protein (10-20 $\mu \mathrm{g}$ ) were loaded onto $4-15 \%$ or $4-20 \%$ gradient precast gels (Bio-Rad), depending on the molecular weight of the target protein. Separated proteins were transferred onto polyvinylidene difluoride membrane by electrotransfer. Membranes were incubated overnight with primary antibodies. We detected target proteins with chemiluminescence ECL system (GE Healthcare) by using secondary antibodies conjugated with horseradish peroxidase (Jackson ImmunoResearch). We next stripped the blots with stripping buffer (2.5\% SDS, 0.7\% 2-mercaptoethanol, 62.5 mм Tris- $\mathrm{HCl}, \mathrm{pH}$ 6.8) and incubated with $\beta$-actin antibody (catalog \#A5316, Sigma), followed by secondary antibody and detection with chemiluminescence ECL system. As described previously (Ballabh et al., 2007), the blots from each experiment were densitometrically analyzed using ImageJ. Optical density (OD) values were normalized to $\beta$-actin, and graphs were presented as "adjusted OD." To combine data for one molecule from multiple Western blots (human tissues), the adjusted OD measurements of the brain regions were normalized such that mean values of "no IVH" cortex samples were equal to 1, and graphs were presented as "relative OD." Antibodies used for Western blot analyses were the same as for immunohistochemistry.

Quantitative real-time PCR. Gene expression was quantified by quantitative real-time PCR (qRT-PCR) as described previously (Ballabh et al., 2007). Briefly, total RNA was isolated using a RNeasy Mini kit (catalog \#74104, Qiagen) from a thin coronal brain slice taken at the level of the mid-septal nucleus. cDNA was synthesized using Superscript II RT (catalog \#05081955001, Roche), and SYBR green (catalog \#04913850001, Roche) was used for amplification with an ABI Prism 7900HT Sequence Detection System (Applied Biosystems). Analysis was completed using the efficiency corrected $\Delta \Delta \mathrm{Ct}$ method. The following primers were used: deiodinase- 2 (accession number: NM_001256300.1), sense: GCTGACCGCATGGACAATAA, antisense: GGACCTTTCCTCCCAGATA; deiodinase-3 (accession number: XM_002721708.1), sense: CAGCGCATCCTCGACTAC, antisense: CGCCTCCTCAATGTAGATGAT; GFAP (accession number: NG_008401), sense: ACTCAATGCTGGCTTCAAGGAGAC, antisense: ATGTAGCTGGCAAAGCGGTCATTG; ID2 (accession number: XM_002723742.1), sense: CCATGAGCCTGCTCTACAA, antisense: GTGCTGCAGGATTTCCATTT; ID4 (accession number: NM_001546), sense: GGCATAATGGCAAATCCTTCAAG, antisense: TCACAAGAGATGGGA CAGTAGC; Olig1 (accession number: XM_002716810.1), sense: AGGTCATCCTGCCCTACTC, antisense: CCAGCAGCAGGATGTAGTT; Olig2 (accession number: XM_002716698.1), sense: TTCAAGTCCTCCTCGTCCA, antisense GGCTCGGTCATCTGTTTCTT; Sox10 (accession number: XM_002723532), sense: AAGCCTTTCTGTCTGGCTCACT, antisense: TCAGGTCCTGGATAGAGGGTCATT; thyroid receptor $\alpha$ (accession number: EU489476.1), sense: CCACCGCAAACACAACATTC, antisense: CTCGACTTTCATGTGGAGGAAG; and thyroid receptor $\beta$ (ac- 

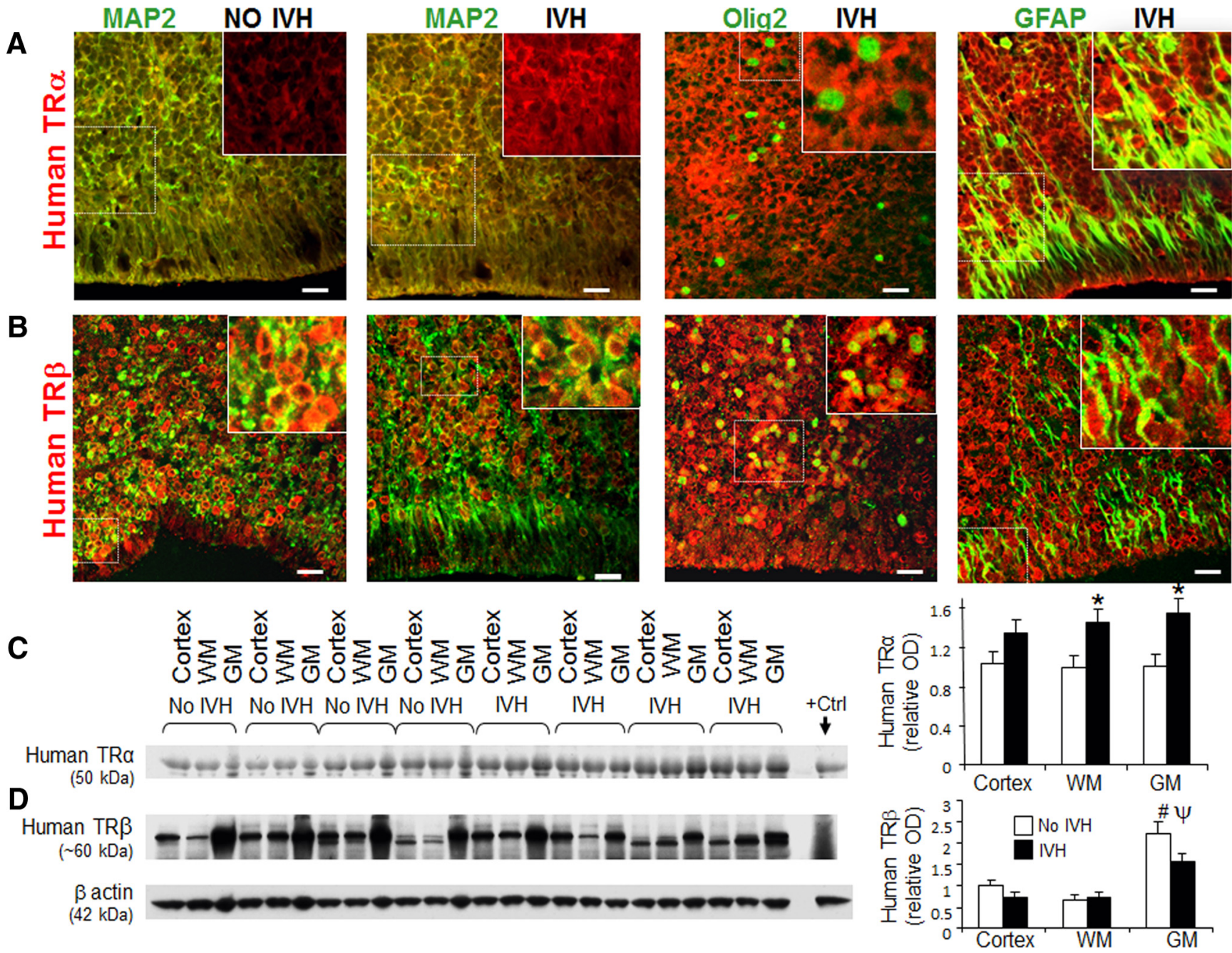

Figure 1. Thyroid hormone receptor $\alpha$ increased after IVH in preterm human infants. $A$, Representative immunofluorescence of cryosections from the germinal matrix of $23-27 \mathrm{gw}$ infants with and without IVH, double labeled with TR $\alpha$ and MAP2/0lig2/GFAP-specific antibodies. Note that TR $\alpha$ expression colocalized extensively with MAP2 ${ }^{+}$cells, but occasionally with 0 lig2 ${ }^{+}$or GFAP ${ }^{+}$ cells. TR $\alpha$ immunoreactivity was stronger in infants with IVH compared with controls, shown in insets at high magnification. $\boldsymbol{B}$, Representative cryosections from the germinal matrix were double labeled with TR $\beta$ and MAP2/Olig2/GFAP-specific antibodies. Note TR $\beta$ was expressed on MAP2 ${ }^{+}, 0$ lig2 ${ }^{+}$, and GFAP ${ }^{+}$cells. C, Representative Western blot for TR $\alpha$ in infant autopsy samples from the cortex, white matter (WM), and germinal matrix (GM). Rat brain was used as the positive control. Bar graphs show the mean \pm SEM ( $n=9$ each group). Protein concentration normalized to $\beta$-actin. Note the higher expression of TR $\alpha$ in infants with IVH compared with controls without IVH in the white matter and germinal matrix. D, Representative Western blot for TR $\beta$ performed on autopsy samples from preterm infants with and without IVH, as indicated in C. Rat brain was used as the positive control. Bar graphs show the mean \pm SEM ( $n=9$ each group). Protein concentration normalized to $\beta$-actin. Note the lower expression of TR $\beta$ in the germinal matrix of infants with IVH compared with neonates without IVH. ${ }^{*} p<0.01$ for the comparison between IVH and no IVH. ${ }^{\#} p \leq 0.01$ cortex versus GM. ${ }^{*} p \leq 0.01$ WM versus GM. Scale bar, $20 \mu \mathrm{m}$. Insets show images under high magnification. Ctrl, Control.

cession number: EU489478.1), sense: CCAGACAGAAGAGAAGAGATGC, antisense: CGTGATACAGCGGTAGTGATAC. Housekeeping genes included GAPDH (accession number: NM_001082253.1), sense: GCGTGAACCACGAGAAGTAT, antisense: CCTCCACAATGCCGAAGT.

Electron microscopy. We processed brains (14 d) from glyceroltreated pups without IVH, pups with IVH, and thyroxine-treated pups with IVH ( $n=3-4$ each). We took slices ( $2 \mathrm{~mm}$ thickness) from freshly harvested rabbit pup brain using a brain slicer matrix and then dissected corona radiata and corpus callosum in a Petri dish under a SteReo discovery microscope (Carl Zeiss). The dissected tissues of the white matter were fixed into $2.5 \%$ glutaraldehyde overnight. The tissues were washed in $0.1 \mathrm{~m}$ sodium cacodylate buffer, $\mathrm{pH} 7.4$, postfixed in buffered osmium tetroxide for 1-2 h, stained en bloc with $1 \%$ uranyl acetate, dehydrated in graded ethanol solutions, and then embedded in epoxy resin. We then placed sections of 60-90 nm thickness onto 200-mesh grids, stained them with uranyl acetate and lead citrate, and then were examined with a Techni 12 electron microscope at $80 \mathrm{kV}$. Digital images were acquired using a 16 megapixel Advanced Microscopy Techniques camera. We acquired 12-20 images per brain. Electron micrographs were evaluated for myelinated axons per unit area; and the g-ratio (ratio of axonal diameter with myelin sheath and axonal diameter without myelin sheath) of myelinated axons in the three groups of pups was computed using ImageJ [National Institutes of Health $(\mathrm{NIH})]$.

Deiodinase activity. D2 assays were performed in frozen rabbit pup brain tissue as described previously (Curcio-Morelli et al., 2003; Huang et al., 2005). Briefly, tissue homogenates were prepared by sonicating them with $10 \mathrm{~mm}$ DTT and $0.25 \mathrm{M}$ sucrose. D2 was assayed using $500 \mathrm{nM}{ }^{125} \mathrm{I}-\left(5^{\prime}\right)$-recombinant $\mathrm{T}_{3}$ (PerkinElmer) and $0.1 \mathrm{nM}$ ${ }^{125} \mathrm{I}-\left(5^{\prime}\right) \mathrm{T}_{4}$ (PerkinElmer), respectively, as substrates and $1 \mathrm{~mm}$ propylthiouracil for D2 measurements. Reactions were stopped by the addition of methanol, and the products of deiodination were quantified by UPLC (ACQUITY, Waters Corp.). Fractions were automatically processed through a Flow Scintillation Analyzer Radiomatic 610TR (PerkinElmer) for radiometry.

Statistics and analysis. Data are expressed as the mean \pm SEM. To determine differences in the myelin basic protein, myelin-associated glycoprotein, and CNPase on Western blot analyses and stereology, we used 

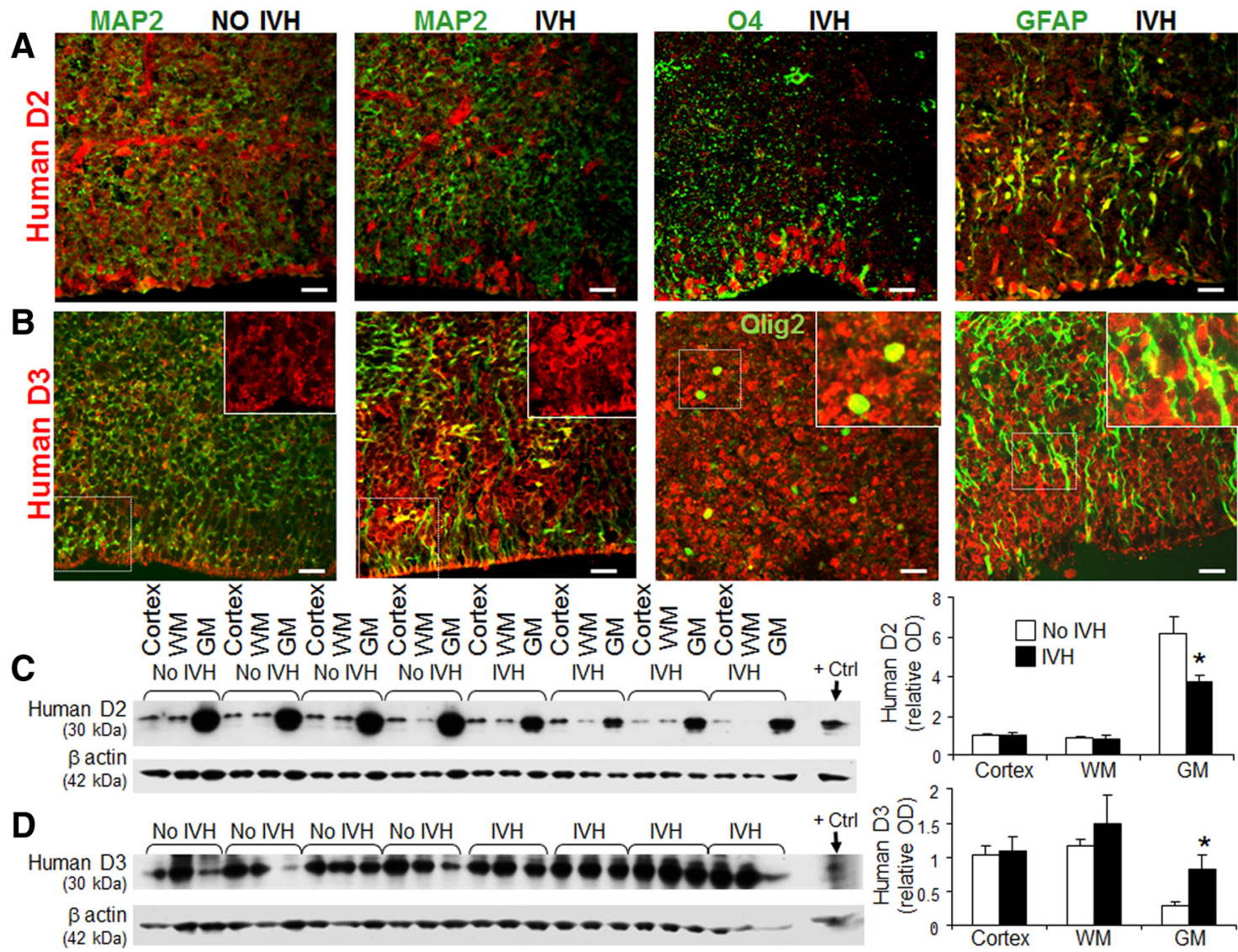

Figure 2. D2 decreased and D3 increased after IVH in preterm human infants. A, Representative immunofluorescence from the germinal matrix of 23-27 gw infants with and without IVH, double labeled with D2 and MAP2/04/GFAP-specific antibodies. Note that D2 is expressed in GFAP ${ }^{+}$astrocytes and radial glia, but is almost absent in MAP2 ${ }^{+}$neurons and $04^{+} 0 \mathrm{OLs}$. $\boldsymbol{B}$, Representative cryosections from the germinal matrix double labeled with D3 and MAP2/0lig2/GFAP-specific antibodies. D3 is abundantly expressed on 0 lig2 ${ }^{+} 0 \mathrm{Ls}$, and weakly expressed on MAP2 ${ }^{+}$and GFAP ${ }^{+}$ cells. Note the higher D3 immunoreactivity in infants with IVH versus infants without IVH. C, Representative Western blot analysis of D2 in cortex, white matter (WM), and germinal matrix (GM) from infants with and without IVH. Rat brain was used as the positive control. Bar graphs show the mean \pm SEM ( $n=9$ each group). Protein concentration was normalized to $\beta$-actin. Note the higher expression of $\mathbf{D} 2$ in the germinal matrix compared with cortex and white matter. $\boldsymbol{D}$, Western blot analysis was performed for $\mathbf{D} 3$ on tissues samples from the three brain regions, as indicated in $\boldsymbol{C}$. Rat brain was used as the positive control. Bar graphs show the mean $\pm \operatorname{SEM}(n=9$ each group). Protein concentration was normalized to $\beta$-actin. Note the higher expression of D3 in the germinal matrix of infants with IVH compared with infants without IVH. ${ }^{*} p<0.05$ for the comparison between IVH and no IVH. Scale bar, $20 \mu \mathrm{m}$.

one-way ANOVA. To compare $\operatorname{TR} \alpha, \operatorname{TR} \beta, \mathrm{D} 2$, and $\mathrm{D} 3$ in the three brain regions, between pups with and without IVH, we used two-way ANOVA with repeated measures. The repeated factor was applied to the following three brain regions: germinal matrix, white matter, and cortex. All post hoc comparisons to test for differences between means were performed using Tukey's multiple-comparison test at the 0.05 significance level. For two-group comparisons, either $t$ test or Mann-Whitney $U$ test was performed, as applicable

\section{Results}

IVH increases expression of thyroid hormone receptor- $\alpha$, but not receptor- $\beta$, in humans

The effect of $\mathrm{TH}$ is mediated via TRs, which are transcription factors with ligand-modulated activity (Sarliève et al., 2004). We evaluated TR $\alpha$ and TR $\beta$ in autopsy samples from preterm infants (23-27 gw) with and without IVH in the following three brain regions: germinal matrix, embryonic white matter, and neocortical mantle (cortex). Immunolabeling showed that $\mathrm{TR} \alpha$ receptors were expressed abundantly on $\mathrm{MAP} 2{ }^{+}$neurons and weakly on Olig $2^{+}$cells in the germinal matrix. GFAP ${ }^{+}$radial glia and astrocytes also expressed $\operatorname{TR} \alpha$ (Fig. $1 A$ ). In the cerebral cortex and white matter, immunoreactivity for $\operatorname{TR} \alpha$ was noted in $\mathrm{MAP}^{+}{ }^{+}$neurons and $\mathrm{GFAP}^{+}$astrocytes. TR $\alpha$ immunoreactivity was more intense in infants with IVH compared with controls without IVH in germinal matrix and the periventricular white matter. Western blot analyses confirmed that $\mathrm{TR} \alpha$ expression was higher in the germinal matrix and white matter of infants with IVH compared with controls without IVH $(p=0.01$ and 0.009 , respectively) but not in the cortex (Fig. 1C). However, TR $\alpha$ expression was comparable among the three brain regions within each group.

Immunohistochemistry revealed that $\mathrm{TR} \beta$ was abundantly expressed in $\mathrm{MAP} 2{ }^{+}$neurons and Olig2 ${ }^{+}$OLs, but scarcely on $\mathrm{GFAP}^{+}$astrocytes in the germinal matrix (Fig. $1 B$ ). The immunoreactivity of $\operatorname{TR} \beta$ was more intense and extensive in the germinal matrix compared with the white matter and cortex. Accordingly, quantification of TR $\beta$ by Western blot analyses indicated that TR $\beta$ levels were higher in the germinal matrix compared with the cortex and white matter in both infants with IVH and without IVH $(p \leq 0.01$, all; Fig. $1 D)$. Interestingly, TR $\beta$ expression was reduced in the germinal matrix of infants with IVH relative to infants without IVH $(p=0.002)$, but not in the cortex and white matter.

Consistent with previous literature, both $\operatorname{TR} \alpha$ and $\mathrm{TR} \beta$ receptors are expressed in OLs (Rodríguez-Peña, 1999), and elevation of TR $\alpha$ in infants with IVH might lead to unliganded receptor activity causing effects of hypothyroidism, such as reduced myelination (Bernal, 2007). Even though TR $\alpha$ plays a predominant role in the brain, accounting for $70-80 \%$ of all TRs (Ercan-Fang 
A
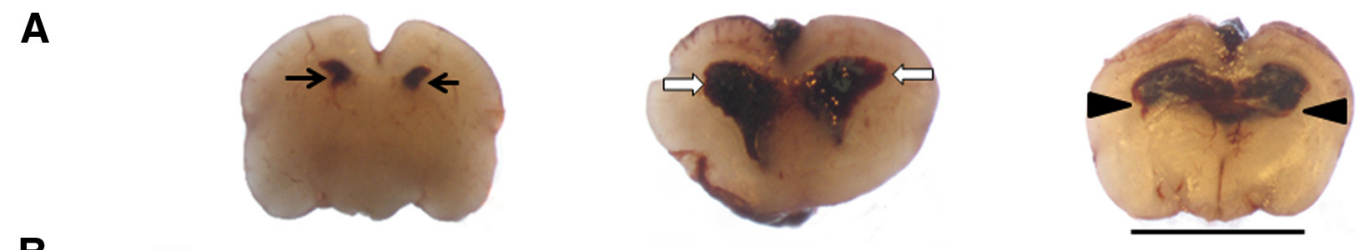

B
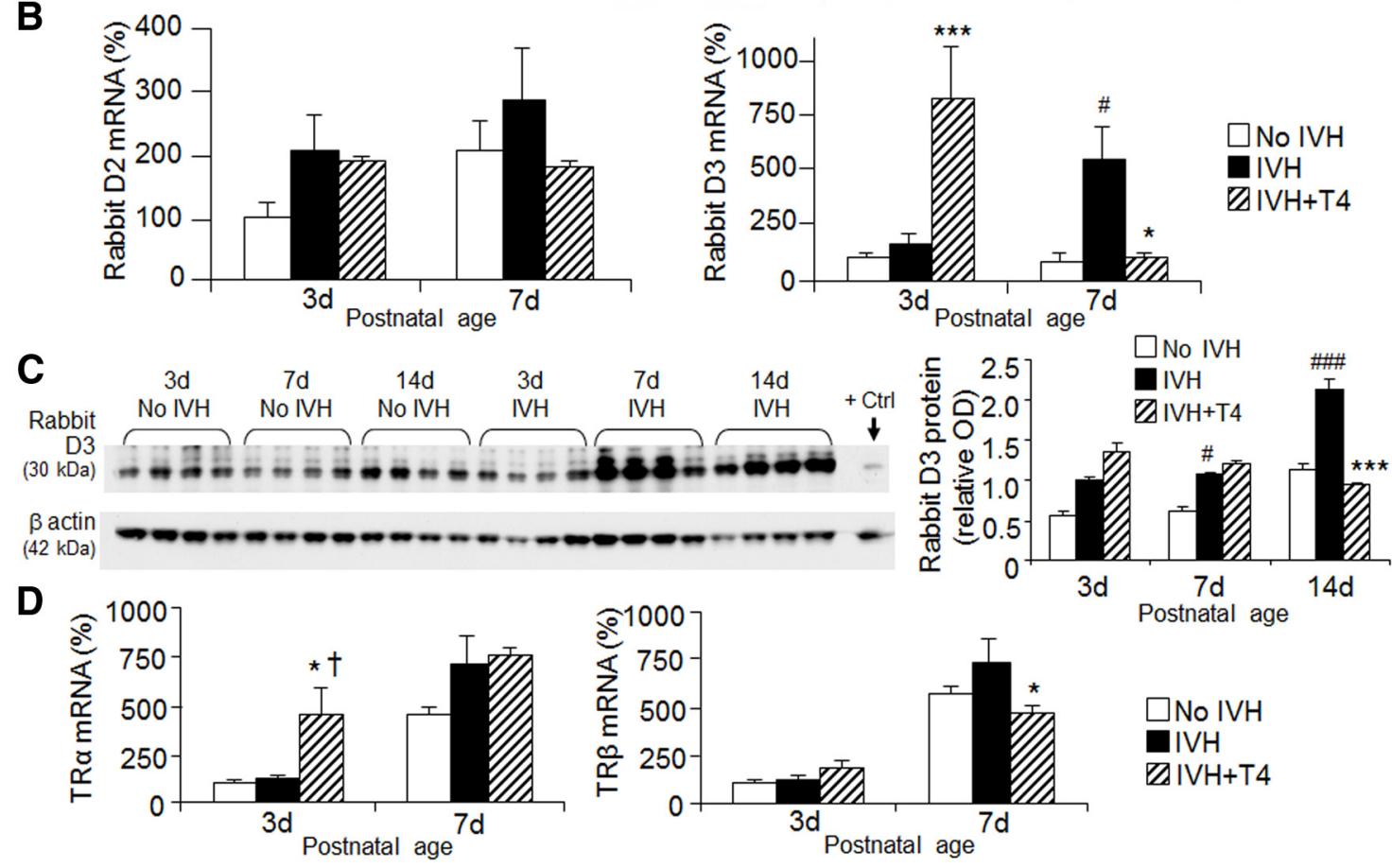

Figure 3. Deiodinase and TR levels in rabbit pups with and without IVH. $\boldsymbol{A}$, Coronal section through the frontal lobe of E29 rabbit pups showing small hemorrhage in the ventricle (arrows; left), moderate hemorrhage in the ventricle (block arrows; middle), and severe hemorrhage resulting in fusion of the two ventricles (arrowheads; right). Scale bar, $1 \mathrm{~cm}$. $\boldsymbol{B}, \mathrm{D} 2$ and D3 $\mathrm{mRNA}$ expression assayed by qRT-PCR ( $n=6$ each group). D2 expression was comparable between pups with and without IVH at both 3 and $7 \mathrm{~d}$. Note the higher D3 expression in pups with IVH than without IVH at $7 \mathrm{~d}$, but not at $3 \mathrm{~d}$. Thyroxine treatment significantly elevated D3 mRNA at $3 \mathrm{~d}$ and reduced it at $7 \mathrm{~d}$. C, Representative Western blot analysis of D3 in rabbit pups with and without IVH. Rat brain was used as the positive control. Bar graphs show the mean \pm SEM ( $n=4$ each group). Protein concentration was normalized to $\beta$-actin. Note the higher expression of D3 in pups with IVH than without IVH at 7 and $14 \mathrm{~d}$, and thyroxine treatment of pups with IVH reduced D3 protein to control levels at $14 \mathrm{~d}$. $D$, TR $\alpha$ and TR $\beta$ mRNA expression assayed by qRT-PCR ( $n=6$ each group). Note that thyroxine treatment elevated TR $\alpha$ expression at $3 \mathrm{~d}$ and reduced TR $\beta$ levels at $7 \mathrm{~d}$ relative to vehicle-treated pups with IVH. ${ }^{\#} p<0.05$, \#\#\# $p<0.001$ for pups with IVH versus without IVH. ${ }^{*} p<$ $0.05,{ }^{* * *} p<0.001$ for vehicle-treated versus thyroxine-treated pups with IVH. ${ }^{\dagger} p<0.05$ for pups with no IVH versus thyroxine-treated pups with IVH.

et al., 1996), reduced levels of $\operatorname{TR} \beta$ in the germinal matrix after IVH might disrupt TH signaling.

\section{IVH induces upregulation of D3 and downregulation of D2 in humans}

$\mathrm{TH}$ acts in a cell-specific manner, and its intracellular activation and deactivation is regulated by D2 and D 3 enzymes, respectively (Gereben et al., 2008). Expression of these enzymes exhibits context-dependent changes after hypoxia-ischemia or oxidative stress (Margaill et al., 2005; Lamirand et al., 2008; Jo et al., 2012). We assessed D2 and D3 expression by immunohistochemistry and Western blot analyses in autopsy materials from preterm infants with and without IVH. We found that D2 was expressed in astrocytes in both germinal matrix and white matter. However, D2 immunoreactivity was weak to absent in $\mathrm{MAP}^{+}{ }^{+}$neurons and $\mathrm{O}^{+}$OLs in the germinal matrix and white matter (Fig. 2A), consistent with previous reports (Courtin et al., 2005). In addition, the immunoreactivity of $\mathrm{D} 2$ appeared to be reduced in the germinal matrix of infants with IVH compared with controls without IVH. Western blot analysis confirmed that the expression of D2 was reduced in the germinal matrix of infants with IVH compared with controls without IVH $(p=0.017)$, but not in the cortex or white matter (Fig. $2 C$ ). Comparison among brain regions revealed that D2 levels were higher in the germinal matrix compared with the cortex or white matter for both infants with and without IVH $(p<0.001$, all). Hence, suppression of D2 in the periventricular germinal matrix might reduce TH activation and, thereby, metabolism in brain cells of infants with IVH.

We next evaluated D3 in immunolabeled brain sections and found that D3 was expressed in most Olig2 ${ }^{+}$cells, some MAP2 ${ }^{+}$ neurons, and sparsely in astrocytes (Fig. 2B). D3 immunoreactivity was higher in the germinal matrix of infants with IVH compared with controls without IVH. Accordingly, Western blot analysis revealed that the levels of D3 were greater in infants with IVH compared with controls without IVH in the germinal matrix $(p=0.049)$, but not in the cerebral cortex or white matter (Fig. $2 D$ ). Levels of $\mathrm{D} 3$ were comparable among the three brain regions in infants with IVH. Hence, D3 is expressed in OL progenitors; and the onset of IVH seemingly reduces TH signaling by coordinated upregulation of D3 and downregulation of D2.

D2 and D3 enzymes in rabbit pups with IVH and the effect of thyroxine treatment

We next studied D2 and D3 expression in our preterm rabbit pup model of glycerol-induced IVH (Fig. 3A), and compared these metrics among pups without IVH, vehicle-treated pups with 

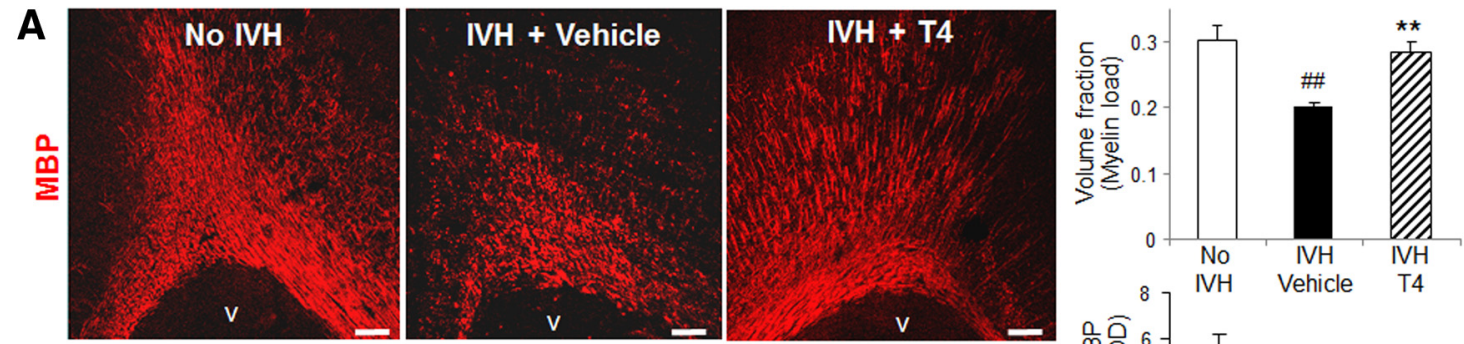

B

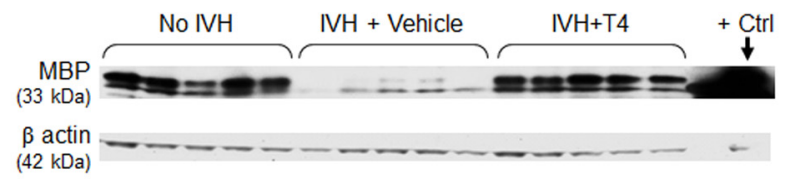

C

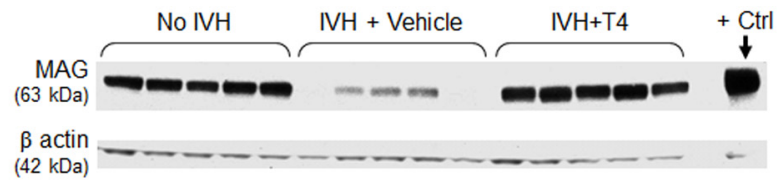

D
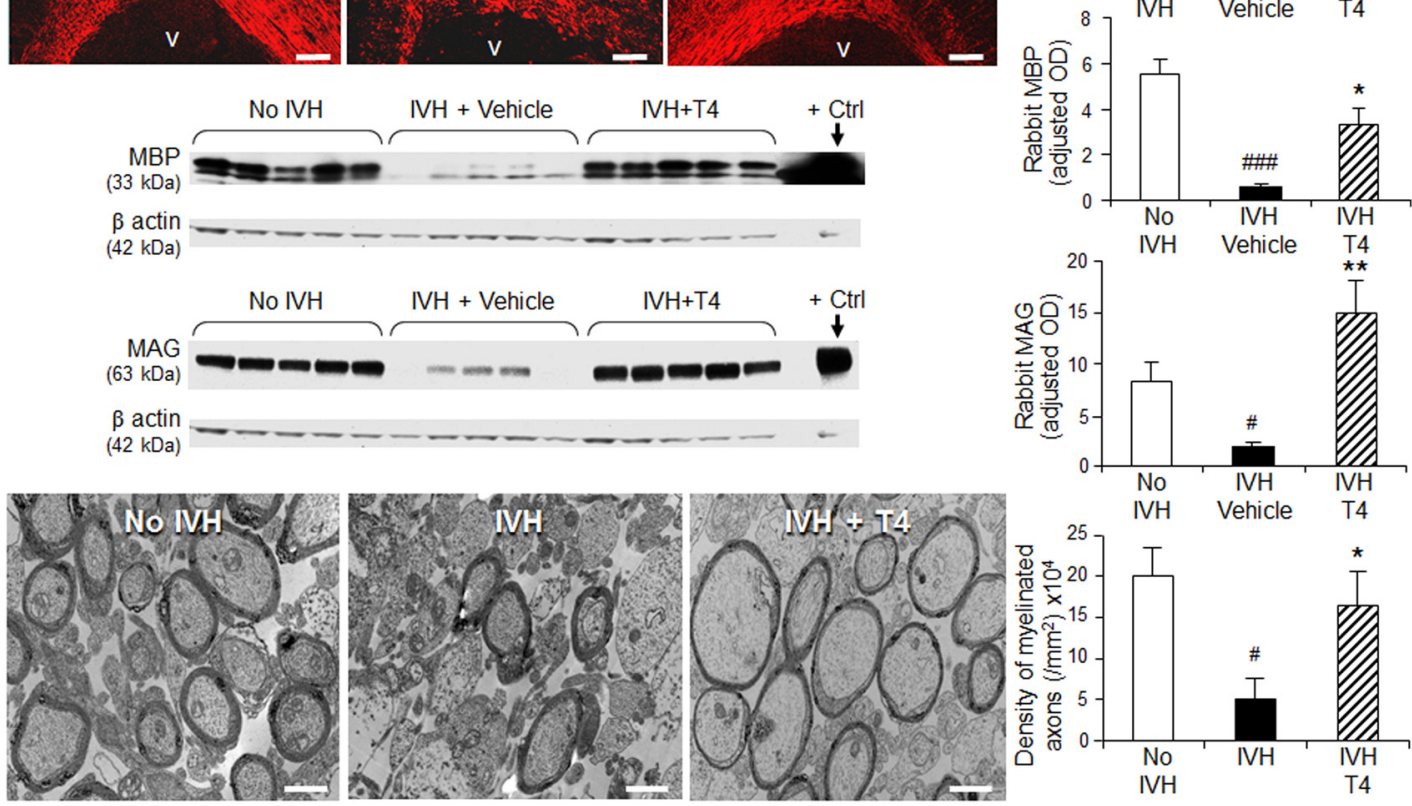

Figure 4. Thyroxine treatment enhances myelination. $A$, Representative immunofluorescence of MBP in the corona radiata of $14 \mathrm{~d}$ pups. Error bars indicate the mean $\pm S E M(~ n=5$ each group). The volume fraction of MBP was elevated in the corpus callosum and corona radiata of thyroxine-treated pups compared with vehicle-treated pups with IVH. Scale bar, $100 \mu \mathrm{m}$. V, Ventricle. $\boldsymbol{B}$, Representative Western blot analysis for MBP in the forebrain of three sets of premature rabbit pups as indicated at $14 \mathrm{~d}$. Adult rat brain was used as the positive control. Each lane represents lysate from a whole coronal slice taken at the level of midseptal nucleus of one brain. The bar graph shows the mean \pm SEM ( $n=5$ each group). MBP expression was higher in thyroxine-treated pups compared with vehicle-treated pups. C, Western blot analysis for MAG in the forebrain of three sets of pups as indicated at $14 \mathrm{~d}$. Adult rat brain was used as the positive control. The bar graph shows the mean \pm SEM ( $n=5$ each group). MAG expression was higher in thyroxine-treated pups compared with vehicle-treated pups. $\boldsymbol{D}$, Typical electron micrograph from rabbit pups without and with IVH, and pups with IVH treated with thyroxine at $14 \mathrm{~d}$. Note that myelinated axons were fewer in pups with IVH relative to controls without IVH, and that thyroxine treatment significantly increased the number of myelinated axons in pups with IVH. Scale bar, $1 \mu \mathrm{m} .{ }^{\#} p<0.05,{ }^{\# \#} p<0.01,{ }^{\# \# \#} p<0.001$, pups with versus without IVH. ${ }^{*} p<0.05,{ }^{* *} p<0.01$, vehicle-treated versus thyroxine-treated pups with IVH.

IVH, and thyroxine-treated pups with IVH. This was important as we chose preterm rabbit pups with IVH to test the effect of thyroxine treatment on myelination and neurological recovery. We assayed D2 mRNA expression by qRT-PCR and found that D2 mRNA was comparable among the three groups at both 3 and $7 \mathrm{~d}$ (Fig. 3B). However, D2 activity was reduced in pups with IVH compared with controls without IVH at $7 \mathrm{~d}$ (no IVH $=3.57 \pm$ $0.46 \mathrm{fmol} / \mathrm{mg} / \mathrm{h} ; \mathrm{IVH}=1.96 \pm 0.23 \mathrm{fmol} / \mathrm{mg} / \mathrm{h} ; p=0.013)$; indeed, D2 is known to be regulated mostly by posttranslational mechanisms (Gereben et al., 2008). In contrast, D3 mRNA was higher in pups with IVH relative to pups without IVH at $7 \mathrm{~d}$, but not at $3 \mathrm{~d}$ (Fig. $3 \mathrm{~B}$ ). Interestingly, thyroxine increased D3 mRNA in-treated pups compared with vehicle controls with IVH at $3 \mathrm{~d}$ $(p<0.001)$; however, D3 levels at $7 \mathrm{~d}$ were reduced in thyroxinetreated pups compared with vehicle controls $(p=0.022 ;$ Fig. $3 B)$. Accordingly, Western blot analyses showed that D3 protein levels were significantly elevated at 7 and $14 \mathrm{~d}$ in pups with IVH compared with controls without IVH $(p<0.02$ and 0.001 , respectively; Fig. $3 C$ ). In addition, D3 protein was significantly reduced in thyroxine-treated pups compared with vehicle controls at $14 \mathrm{~d}$ $(p<0.001)$, but not at 3 or $7 \mathrm{~d}$. D3 activity could not be reliably measured in pups with IVH as blood contamination in brain samples affected inner ring catalysis. Together, these data indicate that (1) rabbit pups with IVH exhibit higher D3 expression and reduced D2 enzyme activity, similar to humans, and that (2) thyroxine treatment reduces D3 protein levels with an initial transient elevation in mRNA. Reduction of D3 by thyroxine is likely to reflect an improvement in the neurological condition of-treated premature newborns with IVH.

\section{TR $\alpha$ and TR $\beta$ receptors in rabbits with IVH and the effect of} thyroxine treatment

Since $\mathrm{TH}$ acts via $\operatorname{TR} \alpha$ and $\operatorname{TR} \beta$, and as thyroxine treatment affects TR expression during development in animal models ( $\mathrm{Ka}$ namori and Brown, 1992; Grommen et al., 2008), we evaluated the expression of TH receptors in pups without IVH, vehicletreated pups with IVH, and thyroxine-treated pups with IVH. We found that mRNA expression of both $\operatorname{TR} \alpha$ and $\operatorname{TR} \beta$ receptors was comparable between pups with and without IVH (Fig. $3 D$ ). Since qRT-PCR was performed on mRNA isolated from a coronal brain slice and not from specific brain regions, these data cannot be directly compared with those of humans. Importantly, $\operatorname{TR} \alpha$ mRNA expression was significantly increased in thyroxinetreated pups with IVH compared with both vehicle-treated pups with IVH and controls without IVH at $3 \mathrm{~d}(p=0.046$ and 0.029 , respectively) but not at $7 \mathrm{~d}$ (Fig. $3 D$ ). In contrast, TR $\beta$ mRNA expression was significantly reduced in thyroxine-treated pups with IVH relative to vehicle-treated pups with IVH at $7 \mathrm{~d}$ ( $p=$ 
0.003), but not at $3 \mathrm{~d}$ (Fig. 3D). Together, thyroxine treatment causes a transient increase in TR $\alpha$ expression and delayed suppression of TR $\beta$ mRNA in pups with IVH. Our data are consistent with a previous report that thyroxine induces expression of D3 mediated by TR $\alpha$ (Barca-Mayo et al., 2011).

\section{Thyroid hormone treatment restores myelination in rabbit pups with IVH}

TH regulates OL specification and differentiation (Baas et al., 1997; Horn and Heuer, 2010); thus, we postulated that thyroxine treatment would restore myelination in preterm pups with IVH compared with vehicle controls. To this end, we compared the following three groups of rabbit pups at $14 \mathrm{~d}$ : (1) glycerol-treated pups without IVH; (2) vehicle-treated pups with IVH; and (3) thyroxine-treated pups with IVH. We performed stereological quantification of myelin in brain sections labeled with MBPspecific antibody and Western blot analyses of homogenates from a forebrain slice taken at the level of the midseptal nucleus. Stereological analyses revealed that the volume fraction (load) of MBP in the corpus callosum and corona radiata was reduced in pups with IVH compared with controls without IVH $(p<0.01)$, and thyroxine treatment restored the myelin load ( $p=0.003$; Fig. $4 A$ ). Accordingly, Western blot analyses showed that MBP levels were reduced in pups with IVH compared with controls without IVH $(p<0.001)$ and that thyroxine treatment of pups with IVH significantly enhanced MBP expression compared with vehicletreated pups with IVH ( $p=0.013$; Fig. $4 B)$.

To further confirm the effect of thyroxine treatment on myelination, we compared the expression of MAG in the same three sets of animals as above. MAG levels were significantly higher in thyroxine-treated rabbit pups with IVH compared with vehicletreated controls with IVH ( $p=0.004$; Fig. $4 C)$. Collectively, thyroxine treatment significantly enhanced $\mathrm{MBP}$ and $\mathrm{MAG}$ expression in pups with IVH.

\section{Thyroid hormone treatment enhances myelination on ultrastructural evaluation}

To determine morphological recovery of myelination after thyroxine treatment in pups with IVH, we assessed myelin in electron microscopy images from the same three sets of pups as above at $14 \mathrm{~d}$ (Fig. $4 D)$. We found that myelinated axons were fewer in pups with IVH relative to controls without IVH $(p=0.02)$ and that thyroxine treatment significantly increased the number of myelinated axons in pups with IVH $(p<0.05)$. Moreover, the g-ratio was comparable in the three groups of pups $(0.77 \pm 0.01$ vs $0.76 \pm 0.002$ vs $0.78 \pm 0.01$, in pups without IVH, with IVH and thyroxine treatment, respectively). This suggests that thyroxine treatment enhances myelination and restores normal morphology of the myelin sheath.

\section{Thyroid hormone treatment enhances neurological recovery}

To determine whether thyroxine treatment promotes neurological recovery in rabbit pups with IVH, we performed neurobehavioral evaluations on the same three sets of preterm pups at $14 \mathrm{~d}$ (Table 3), based on a previously described protocol (Chua et al., 2009). The severity of IVH, quantified by head ultrasonography, was comparable in thyroxine- and vehicle-treated pups. We noted significant weakness in the foreleg of one and the hindlegs of three vehicle-treated pups with IVH (31\%), whereas one pup in the thyroxine-treated group (9\%) had weakness in the hindlegs manifesting as clumsiness in the gait. The scores for gait were significantly higher in thyroxine-treated pups than in vehicletreated IVH controls $(p<0.05)$. The average distance walked in
Table 3. Neurobehavioral evaluation of thyroxine-treated pups compared to vehicle-treated controls with IVH and pups without IVH at postnatal day 14

\begin{tabular}{|c|c|c|c|c|}
\hline System & Test & $\begin{array}{l}\text { № IVH } \\
(n=12)\end{array}$ & $\begin{array}{l}\text { IVH } \\
(n=12)\end{array}$ & $\begin{array}{l}\text { IVH + thyroxine } \\
(n=11)\end{array}$ \\
\hline \multirow{3}{*}{$\begin{array}{l}\text { Cranial } \\
\text { nerve }\end{array}$} & Aversive response to alcohol & $3(3-3)$ & $3(3-3)$ & $3(3-3)$ \\
\hline & Sucking and swallowing & $3(3-3)$ & $3(3-3)$ & $3(3-3)$ \\
\hline & Vision & $3(3-3)$ & $3(3-3)$ & $3(3-3)$ \\
\hline \multirow[t]{13}{*}{ Motor } & Motor activity & & & \\
\hline & Head & $3(3-3)$ & $3(3-3)$ & $3(3-3)$ \\
\hline & Forelegs & $3(3-3)$ & $3(3-3)$ & $3(3-3)$ \\
\hline & Hindlegs & $3(3-3)$ & $3(1.75-3)$ & $3(3-3)$ \\
\hline & Righting reflex ${ }^{a}$ & $5(5-5)$ & $3(3-5)$ & $5(5-5)^{*}$ \\
\hline & Locomotion on $30^{\circ}$ inclination ${ }^{b}$ & $3(3-3)$ & $3(2-3)$ & $3(3-3)$ \\
\hline & Tone' forelimb & $0(0-0)$ & $0(0-0)$ & $0(0-0)$ \\
\hline & Tone': hindlimb & $0(0-0)$ & $0(0-0)$ & $0(0-0)$ \\
\hline & $\begin{array}{l}\text { Ability to hold their position at } 60^{\circ} \\
\text { inclination (latency to slip down, s) }\end{array}$ & $17.8 \pm 0.6$ & $13.4 \pm 1.4$ & $23 \pm 2.1^{*}$ \\
\hline & Distance walked in $60 \mathrm{~s}$ (inches) & $94 \pm 14.1$ & $55 \pm 9.6^{\#}$ & $114 \pm 15.6^{*}$ \\
\hline & $\begin{array}{l}\text { Inability to walk }>40 \text { inches in } \\
1 \mathrm{~min}(\%)\end{array}$ & 0 & 31 & 9 \\
\hline & Gait $^{d}$ & $4(4-4)$ & $3(2-4)^{\#}$ & $4(4-4)^{* *}$ \\
\hline & Motor impairment (\%) ${ }^{e}$ & 0 & 31 & 9 \\
\hline \multirow[t]{2}{*}{ Sensory } & Facial touch & $3(3-3)$ & $3(3-3)$ & $3(3-3)$ \\
\hline & Pain & $3(3-3)$ & $3(3-3)$ & $3(3-3)$ \\
\hline
\end{tabular}

Values are the median (interquartile range) or mean \pm SEM, unless otherwise stated. Zero is the worst response, and 3 is the best response, unless otherwise noted.

${ }^{a}$ Score (range, 1-5): number of times of five tries turn prone within $2 \mathrm{~s}$ when placed in supine position.

${ }^{b}$ Score (range, $0-3$ ) 0, does not walk; 1 , takes a few steps ( $<8$ inches); 2 , walks for $9-18$ inches; 3 , walks very well beyond 18 inches.

'Score (range, 1-3): 0 , no increase in tone; 1, slight increase in tone; 2, considerable increase in tone; 3 , limb rigid in flexion or extension.

${ }^{d}$ Gait was graded as 0 (no locomotion); 1 (crawls with trunk touching the ground for few steps and then rolls over); 2 (walks taking alternate steps, trunk low, and cannot walk on inclined surface); 3 (walks taking alternate steps, cannot propel its body using the hind legs synchronously, but walks on $30^{\circ}$ inclined surface); 4 (walks, runs, and jumps without restriction, propels the body using synchronously the back legs, but has limitation in speed, balance, and coordination, manifesting as clumsiness in gait); or 5 (normal walking).

${ }^{e}$ Motor impairment was defined as weakness in either forelegs or hindlegs and a distance walked of $<40$ inches in $60 \mathrm{~s}$.

${ }^{*} p<0.01,{ }^{* *} p<0.05$, vehicle-treated versus thyroxine-treated pups with IVH.

${ }^{\#} p<0.05$, glycerol-treated pups without IVH versus vehicle-treated pups with IVH.

$60 \mathrm{~s}$ was farther in thyroxine-treated pups compared with vehicle controls $(p=0.011)$. The latency to slip down a ramp pitched at $60^{\circ}$ inclination was substantially longer in the thyroxine-treated pups relative to vehicle controls $(p<0.05)$. Scores for the righting reflex were significantly better in thyroxine-treated pups compared with vehicle-treated controls $(p<0.009)$. No difference was observed in sensory and cranial nerve assessment of the three sets of rabbit pups. Importantly, we did not observe any apparent adverse effect attributable to thyroxine treatment among pups with IVH receiving this medication.

\section{Thyroid hormone treatment did not affect gliosis}

Since TH controls the production of OLs and astrocytes in the developing brain by acting on their common precursors, we postulated that thyroxine treatment would reduce gliosis (Sharlin et al., 2008). Therefore, we compared gliosis among three sets of 14-d-old rabbit pups in a similar manner as for myelin. GFAPlabeled brain sections were assessed by unbiased stereology, and GFAP was quantified in homogenates from brain slices taken at the level of the midseptal nucleus by Western blot analysis. For stereological evaluation of gliosis, we measured the total volume fraction of astrocytes and glial fibers in brain sections labeled with GFAP. We found that the volume fraction (load) of astrocyte cell bodies and glial fibers was comparable between vehicle- and thyroxine-treated pups with IVH in the corpus callosum and corona radiata (Fig. 5A). Consistent with stereological findings, 

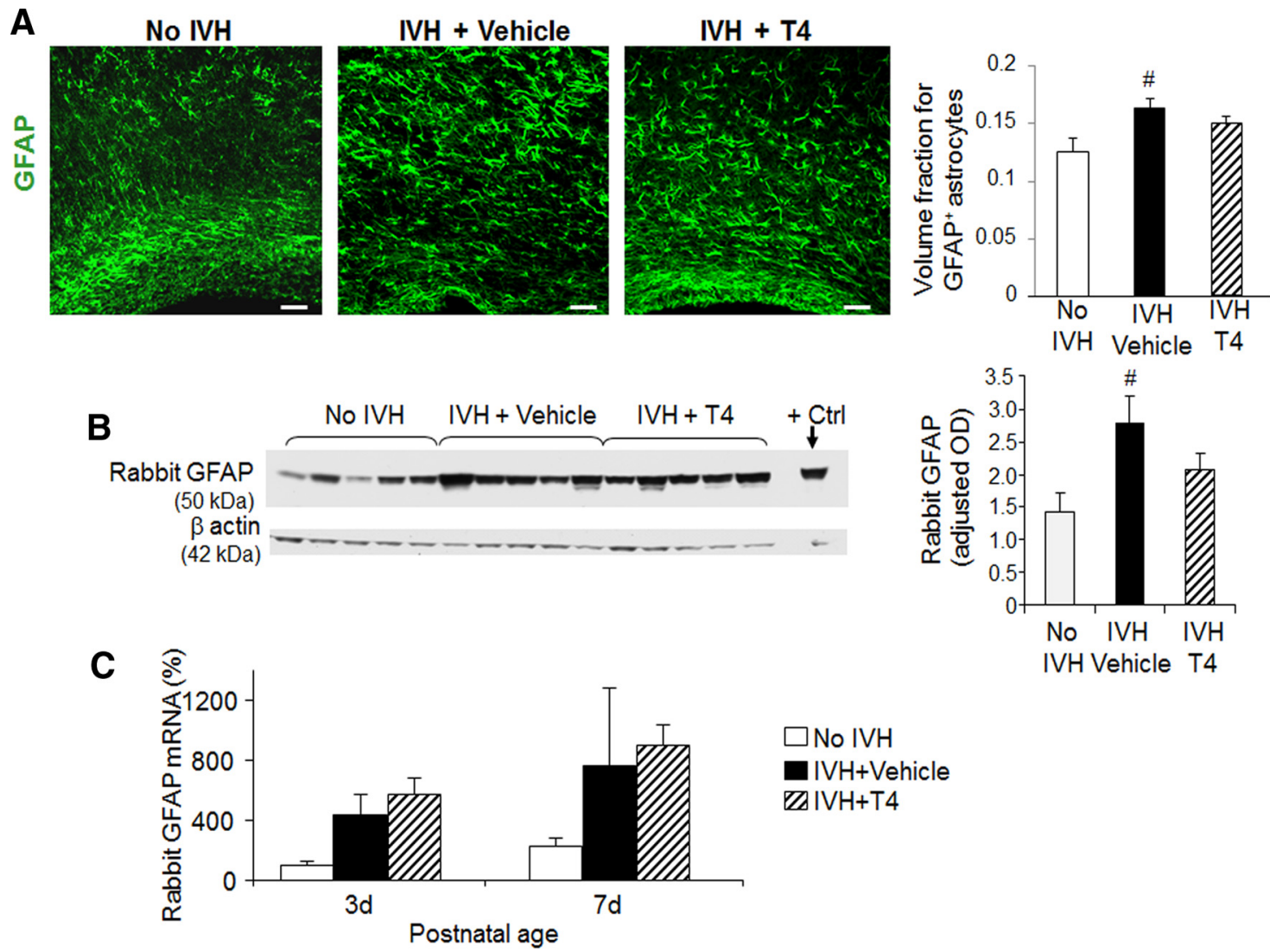

Figure 5. Thyroxine treatment does not affect gliosis. A, Typical appearance of GFAP labeling in the groups of pups indicated at $14 \mathrm{~d}$. Bar graphs show the mean \pm SEM. Note the increased volume fraction (load) of astrocytes and glial fibers in pups with IVH compared with controls, and no effect of thyroxine treatment in pups with IVH. Scale bar, $50 \mu \mathrm{m}$. $\boldsymbol{B}$, Representative Western blot analysis for GFAP in the groups of pups indicated at $14 \mathrm{~d}$. Bar graphs are the mean \pm SEM ( $n=5$ each group). Protein concentration normalized to $\beta$-actin. Rat brain was used as the positive control. Levels of GFAP were elevated in pups with IVH compared with controls, and thyroxine treatment did not alter GFAP levels in pups with IVH. C, Gene expression of GFAP assayed by qRT-PCR at 3 and $7 \mathrm{~d}$. Note that IVH elevates the transcription of GFAP at $3 \mathrm{~d}$, and that thyroxine does not affect GFAP mRNA expression in pups with IVH. ${ }^{\#} p<0.05$, pups with versus without IVH.

Western blot analyses revealed similar levels of GFAP in thyroxine- and vehicle-treated pups with IVH (Fig. 5B). GFAP mRNA accumulation also showed a trend toward an increase in vehicle- and thyroxine-treated pups with IVH compared with controls without IVH, but the difference was not significant (Fig. $5 C$ ). Collectively, thyroxine treatment did not affect astrocytosis in rabbit pups with IVH.

\section{Thyroid hormone treatment enhances proliferation and maturation of oligodendrocytes}

Thyroxine treatment affects the proliferation of OLs in a contextdependent manner and enhances maturation of OLs in adult models of demyelination (Giardino et al., 2000; Franco et al., 2008). The finding that thyroxine treatment enhanced myelination led us to question whether thyroxine promoted proliferation or maturation of OLs in our developmental model of IVH.

To assess proliferation, we immunolabeled brain sections from the following three sets of animals: (1) glycerol-treated controls without IVH; (2) vehicle-treated pups with IVH; and (3) thyroxine-treated pups with IVH using two sets of antibodiesOlig2 with Ki67 and PDGFR $\alpha$ with Ki67. We found that the Olig2 count showed a trend toward decline in the germinal matrix of pups with IVH compared with controls without IVH at $3 \mathrm{~d}$ ( $p=$ $0.06)$; and thyroxine treatment of pups with IVH significantly elevated the density of Olig2 ${ }^{+}$cells in this brain region at $3 \mathrm{~d}(p<$ 0.001 ), but not at $7 \mathrm{~d}$ (Fig. $6 \mathrm{~A}$ ). We next evaluated the density of proliferating Olig $2^{+}$cells (both Olig ${ }^{+}$and $\mathrm{Ki}^{+} 7^{+}$) at both 3 and $7 \mathrm{~d}$. Cycling Olig2 ${ }^{+}$cells were reduced in pups with IVH at $3 \mathrm{~d}$ $(p=0.03)$, but not at $7 \mathrm{~d}$. There was no significant difference in cycling Olig $2^{+}$cells between vehicle- and thyroxine-treated pups with IVH.

PDGFR $\alpha^{+}$cells are early OL progenitors that signify specification of undifferentiated precursors into the OL lineage. We assessed the density of total and cycling PDGFR $\alpha^{+}$cells in the white matter in the same three sets of pups at $3 \mathrm{~d}$. The density of total PDGFR $\alpha^{+}$cells in the corona radiata and corpus callosum was comparable between pups with and without IVH, and thyroxine treatment of pups with IVH significantly elevated the total population of PDGFR $\alpha^{+}$cells $(p=0.04$; Fig. $6 B)$. Similarly, thyroxine treatment enhanced the density of proliferating PDGFR $\alpha^{+}$cells in pups with IVH $(p=0.006)$. Together, thyroxine treatment promotes specification of OL progenitors, marked by an increase in the density of PDGFR $\alpha^{+}$cells. In addition, thyroxine accelerates proliferation of these early progenitors.

To examine the effect of thyroxine on maturation of OL progenitors, we evaluated the density of $\mathrm{APC}^{+}$(immature and mature OL marker) and $\mathrm{O}_{4}{ }^{+}$OLs in the corona radiata and corpus callosum of the same three sets of pups at $7 \mathrm{~d}$. Coronal sections double labeled with $\mathrm{O} 4$ and APC antibodies were evaluated. We noted that the density of total $\mathrm{O}^{+}$cells was higher in pups with IVH compared with controls $(p<0.05)$ and that thyroxine treatment did not significantly affect the population of these cells (Fig. 

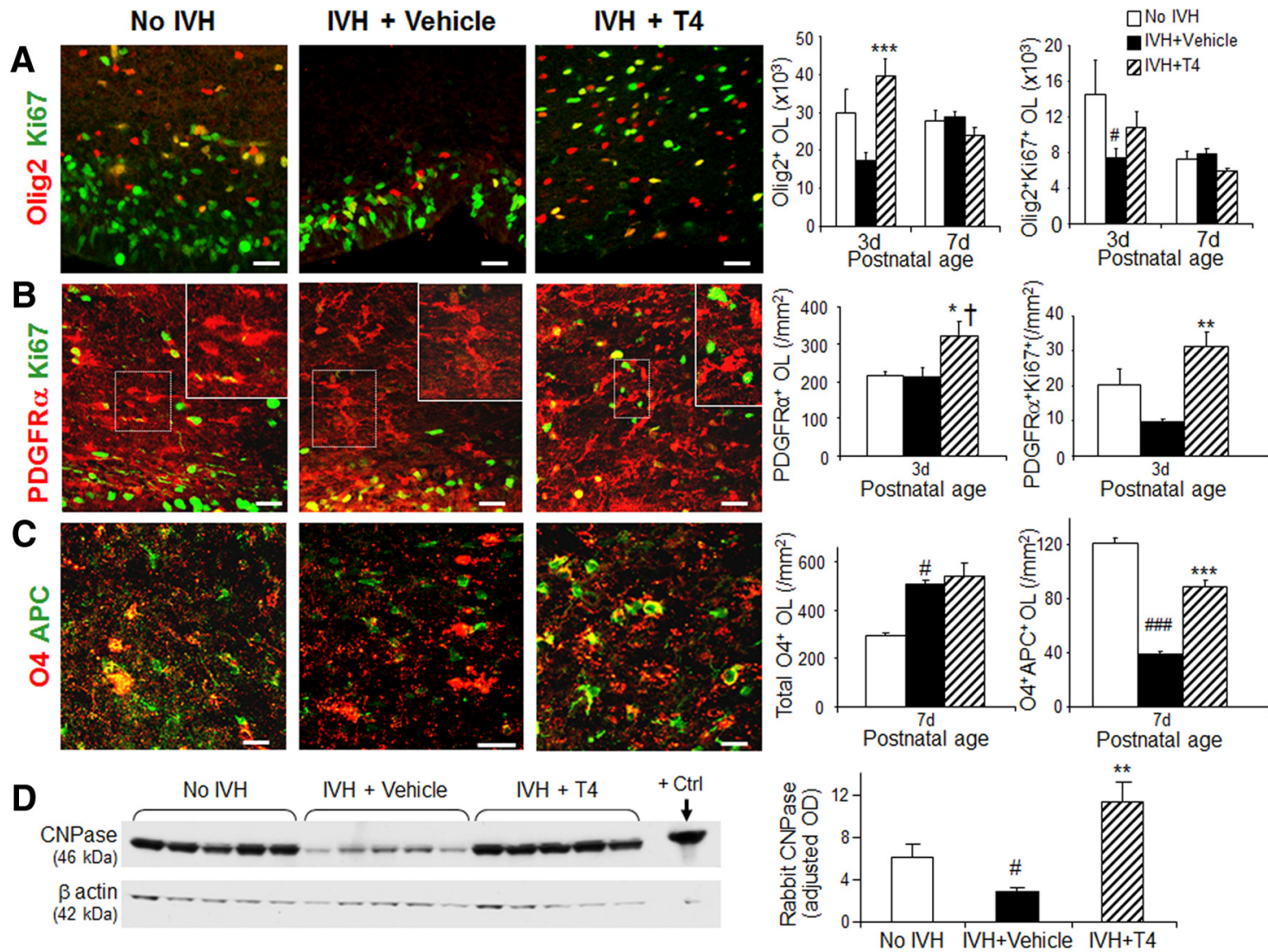

Figure 6. Thyroxine treatment enhances the proliferation and maturation of OLS. A, Representative cryosections from 3-d-old pups double labeled with 0 lig2 and Ki67 antibodies. Bar graphs show the mean \pm SEM ( $n=5$ each group). Note the enhanced density after thyroxine treatment at $3 \mathrm{~d}$, not at $7 \mathrm{~d}$. $\boldsymbol{B}$, Typical double labeling of PDGFR $\alpha$ and Ki67 in the corona radiata and corpus callosum of 3-d-old pups. Bar graphs show the mean \pm SEM ( $n=5$ each group). Note that thyroxine treatment enhances the density of both total and cycling PDGFR $\alpha^{+}$cells. $C$, Representative immunolabeling of the corona radiata of 7-d-old pups using 04- and APC-specific antibodies. Bar graphs show the mean \pm SEM ( $n=5$ each group). $04^{+} \mathrm{APC}{ }^{+}$cells are higher in density in thyroxine-treated pups. $\boldsymbol{D}$, Western blot analyses of CNPase in rabbit pups without IVH and vehicle- or thyroxine-treated pups with IVH. Bar graphs show the mean \pm SEM ( $n=5$ each group). Protein concentration normalized to actin. Thyroxine treatment restores normal levels of CNPase in pups with IVH. Scale bar, $20 \mu \mathrm{m} .{ }^{\#} p<0.05$, \#\#\# $p<0.001$, pups with versus without IVH. ${ }^{*} p<$ $0.05,{ }^{* *} p<0.01,{ }^{* * *} p<0.001$, vehicle-treated versus thyroxine-treated pups with IVH. ${ }^{\dagger} p<0.05$, no IVH versus thyroxine-treated pups with IVH.

6C). More importantly, the population of $\mathrm{O}^{+} \mathrm{APC}^{+}$cells was significantly reduced in pups with IVH compared with controls without IVH $(p<0.001)$, and thyroxine treatment significantly increased the density of $\mathrm{O}_{4}^{+} \mathrm{APC}^{+} \mathrm{OLs}(p<0.001)$ in the corona radiata and corpus callosum. This suggests that thyroxine treatment restores the maturation of OLs in pups with IVH.

Our previous work has shown that IVH arrests maturation of OL progenitors in the pre-OL stage $\left(\mathrm{O}_{4}{ }^{+} \mathrm{CNPase}^{-}\right)$, reducing the density of immature OLs labeled with $\mathrm{O}^{+}$or CNPase $^{+}$ (Dummula et al., 2011). Therefore, we evaluated the effect of thyroxine on the expression of CNPase in pups with IVH at $14 \mathrm{~d}$, using Western blot analysis. We found that the level of CNPase was significantly reduced in pups with IVH compared with controls without IVH $(p<0.05)$ and that thyroxine treatment restored the expression of CNPase at $14 \mathrm{~d}(p=0.002$; Fig. $6 D)$. This confirms that thyroxine treatment restores differentiation of OL progenitors. Together, thyroxine treatment favors the proliferation of early OL progenitors, and promotes both the specification and maturation of OL progenitors, consistent with previous reports (Franco et al., 2008; Harsan et al., 2008).

Thyroid hormone promotes maturation of oligodendrocytes in preterm human infants with IVH

In a double-blinded, placebo-controlled clinical trial, premature infants of 24-28 gw were treated with TH in doses of either 4 or 8 $\mu \mathrm{g} / \mathrm{kg} / \mathrm{d}$ for $42 \mathrm{~d}$ in our Neonatal Intensive Care Unit (La Gamma et al., 2009). This NIH-funded study was performed to enhance the neurodevelopmental outcome of premature infants as extremely premature infants commonly exhibit transient hypothyroxinemia of prematurity. Among the infant deaths in the TH-treated group, brain autopsy samples were obtained from three infants and were compared with matched controls for maturation of OLs by double labeling brain sections with $\mathrm{O} 4$ and $\mathrm{O} 1$ antibodies (Table 2). Premature infants treated with $\mathrm{TH}$ showed a higher percentage of immature OLs $\left(\mathrm{O}_{4}{ }^{+} \mathrm{O} 1^{+}\right)$compared with untreated controls $(37.1 \pm 8.2 \%$ vs $20.8 \pm 4.6 \%$; Fig. 7$)$. These data suggest that $\mathrm{TH}$ treatment in human infants enhances the maturation of OLs.

\section{Thyroxine treatment elevates Olig2 and Sox10 transcription factors}

As OL maturation progresses from specification to terminal differentiation, a number of transcription factors play essential roles in this process. Olig1, Olig2, and Sox10 favor OL maturation, whereas Id 2 and Id 4 have inhibitory influences (Nicolay et al., 2007). We assessed the expression of these transcription factors in a coronal slice from the level of the midseptal nucleus in the following three sets of pups at 3 and $7 \mathrm{~d}$ by qRT-PCR: (1) pups without IVH; (2) vehicle-treated pups with IVH; and (3) thyroxine-treated pups with IVH (Fig. 8). The expression of Sox10 was significantly reduced in pups with IVH at both 3 and $7 \mathrm{~d}(p=0.045$ and 0.03 , respectively), whereas Olig2 mRNA 
accumulation was significantly reduced at $7 \mathrm{~d}(p<0.01)$, not at $3 \mathrm{~d}$. More importantly, thyroxine treatment significantly elevated levels of Sox10 and Olig2 expression compared with vehicle controls at $3 \mathrm{~d}$ ( $p=0.04$ and 0.01 , respectively). Olig1 mRNA expression among the three sets of pups was not statistically significant. Similarly, Id 2 and Id 4 expression did not exhibit significant change after thyroxine treatment. Together, thyroxine treatment restores the expression of Olig2 and Sox10 in pups with IVH.

Thyroxine treatment does not impact apoptosis in pups with IVH or healthy controls

While TH is a survival factor for developing OLs, sustained neonatal hyperthyroidism activates apoptosis (Marta et al., 1998; Jones et al., 2003). We have previously shown that the onset of IVH induces apoptosis, which is mediated by both the intrinsic and extrinsic pathways. Herein, we asked whether thyroxine treatment worsens apoptosis in pups with IVH and without IVH. To obtain an overview of apoptosis, we performed Western blot analysis of caspase 3 (a key mediator of apoptosis). At both 3 and $7 \mathrm{~d}$, we observed that levels of cleaved caspase 3 (activated caspase) were higher in pups with IVH relative to pups without IVH. (Fig. 9A,B). However, thyroxine treatment did not further impact caspase 3 expression in pups with IVH. We next evaluated the effect of thyroxine treatment on caspase activation in healthy pups at $3 \mathrm{~d}$ (Fig. 9C). We were reassured to find that thyroxine treatment did not activate caspase 3 in healthy pups.

To further confirm these findings, we performed TUNEL labeling on vehicle- and thyroxine-treated pups with IVH at $7 \mathrm{~d}$. Consistent with the caspase activity, we found no difference in the density of total $\mathrm{TUNEL}^{+}$cells or Olig ${ }^{+}$cells colabeled with TUNEL between thyroxine- and vehicle-treated pups (Fig. 9D). In conclusion, thyroxine treatment in a dose of $20 \mu \mathrm{g} / \mathrm{kg} / \mathrm{d}$ did not affect programmed cell death in pups with or without IVH.
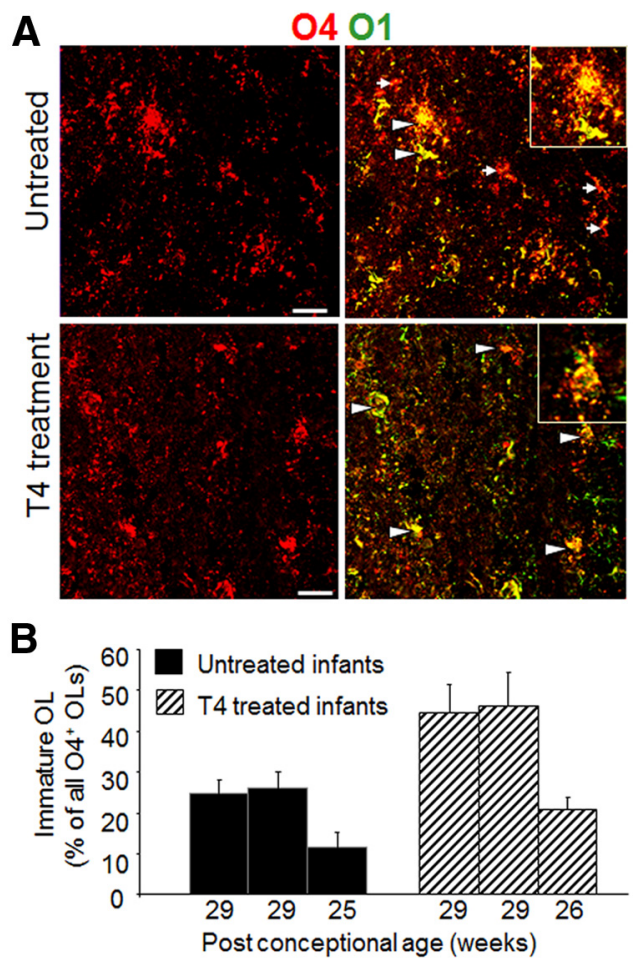

Figure 7. Thyroxine treatment enhances the maturation of $0 \mathrm{Ls}$ in human preterm infants with IVH. $\boldsymbol{A}$, Representative immunofluorescence of cryosections from the white matter of a 25 gw premature infant labeled with 04 and 01 antibodies. Note the higher density of myelinating OLs, double labeled with 04 and 01 (arrowheads), in thyroxine-treated infants compared with untreated controls. Arrows indicate $04^{+} 01^{-}$OLs. Scale bar, $20 \mu \mathrm{m}$. B, Quantification of myelinating (immature) OLs was performed in three thyroxine-treated cases and three matched untreated controls. Each bar represents one case. Data are the mean \pm SEM. Note the higher percentage of immature $0 \mathrm{Ls}$ in thyroxine-treated cases compared with controls.

\section{Thyroxine treatment does not affect maturation of OLs and myelination in healthy controls}

Sustained neonatal hyperthyroidism can accelerate OL progenitor development while decreasing overall proliferation in the brain (Marta et al., 1998; Fernandez et al., 2004a). Thus, we asked whether thyroxine treatment of healthy control pups would alter the proliferation and maturation of OLs, as well as subsequent myelination. To this end, we compared the proliferation of OL progenitors between (1) healthy controls (no glycerol treatment) and (2) thyroxine-treated healthy controls (Fig. 10A). We found that the number of total Olig2 ${ }^{+}$cells in the germinal matrix was comparable between the two groups at both 3 and $7 \mathrm{~d}$. Cycling Olig2 showed a trend toward reduction in thyroxine-treated pups compared with controls $(p=0.09)$, but the comparison was not significant. Importantly, the density of proliferating $\operatorname{PDGFR} \alpha^{+}$cells was significantly reduced in thyroxine-treated pups compared with controls at $3 \mathrm{~d}(p<0.001)$, but not the total number of these cells. Together, thyroxine treatment suppressed the
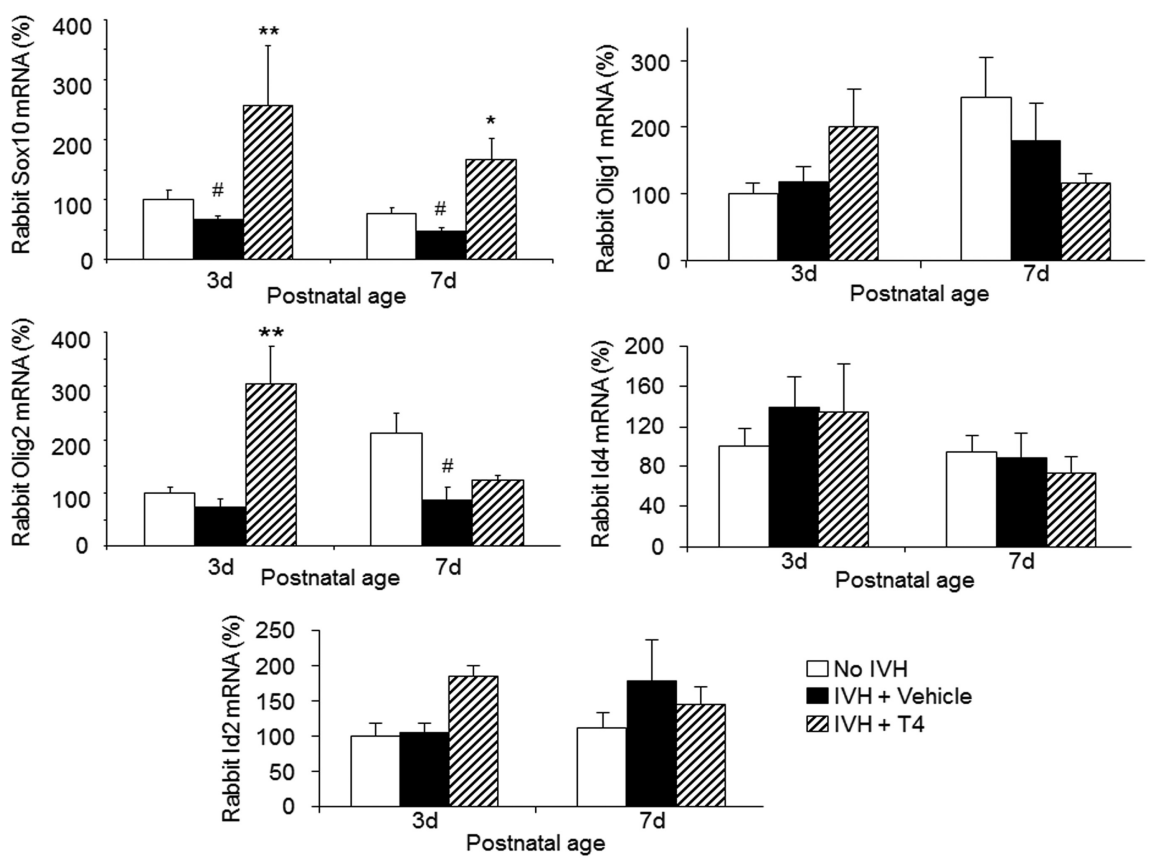

$\square$ No IVH

aIVH + Vehicle

ZIVH + T4

Figure 8. Thyroxine treatment elevates 0lig2 and Sox10 transcription factors. qRT-PCR was performed in pups without IVH as well as vehicle- and thyroxine-treated pups with IVH. Note the reduced expression of 0lig2 and Sox10 mRNA in pups with IVH relative to controls without IVH, and the enhanced expression of 0lig2 and Sox10 genes in thyroxine-treated compared with vehicle-treated pups with IVH. ${ }^{*} p<0.05,{ }^{* *} p<0.01$, vehicle-treated versus thyroxine-treated pups with IVH. ${ }^{*} p<0.05$, pups with versus without IVH. 

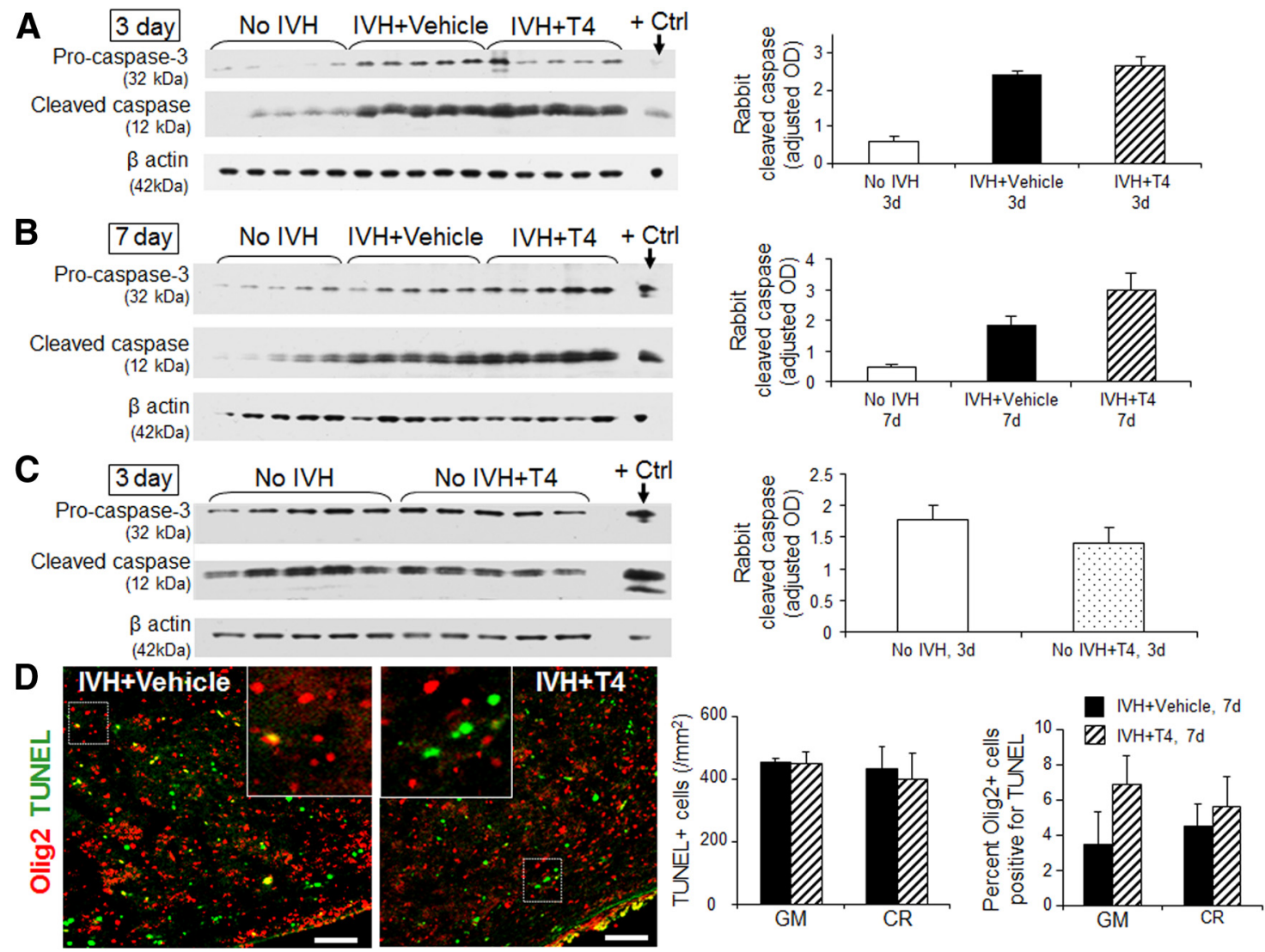

Figure 9. Thyroxine treatment does not affect apoptosis in rabbit pups. $A, B$, Representative Western blot analyses for caspase 3 in the forebrain of three sets of premature rabbit pups as indicated at 3 and $7 \mathrm{~d}$. Bar graphs show the mean \pm SEM ( $n=5$ each group). Protein concentration normalized to $\beta$-actin. Newborn rat brain used as the positive control. Note the elevated cleaved caspase in pups with IVH relative to controls without IVH; and thyroxine treatment does not affect the cleaved caspase level. $C$, Western blot analyses for vehicle-treated and thyroxine-treated healthy pups without IVH at 3 d. Bar graphs show the mean \pm SEM ( $n=5$ each group). Protein concentration was normalized to actin. There is no difference in the cleaved caspase level between the two groups. D, Representative immunofluorescence of 7-d-old rabbit pups labeled with Olig2 and TUNEL. Left, Bar graph shows the mean \pm SEM of the total TUNEL ${ }^{+}$cells in the germinal matrix (GM) and corona radiata (CR) of 7-d-old rabbit pups. Right, Bar graph indicates the mean \pm SEM of the percentage of Olig2 ${ }^{+}$cells that are TUNEL $^{+}$in the GM and CR. No difference was seen in the extent of apoptosis between vehicle-treated or thyroxine-treated pups with IVH. Scale bar, $50 \mu \mathrm{m}$.

proliferation of OL progenitors, but not the total number of these cells.

To examine the effect of thyroxine on maturation of OL progenitors, we evaluated the density of $\mathrm{O}^{+}$and $\mathrm{APC}^{+}$OLs between control pups with and without thyroxine treatment at $7 \mathrm{~d}$. The densities of total $\mathrm{O}_{4}^{+}$and $\mathrm{O}^{+} \mathrm{APC}^{+}$cells were comparable between the groups (Fig. 10A). To further confirm the effect of thyroxine on the maturation of OL progenitors, we performed Western blot analysis for CNPase and found that the levels were similar between the two groups at $14 \mathrm{~d}$ (Fig. 10B). Accordingly, MBP protein expression was comparable in thyroxine-treated and untreated control pups at $14 \mathrm{~d}$ (Fig. 10C). Together, these data suggest that thyroxine treatment reduced proliferation but did not affect maturation of OL progenitors or subsequent myelination at the dose used in this study. Suppression of proliferation after thyroxine treatment has been observed in previous studies (Fernandez et al., 2004a). The failure of thyroxine to affect the maturation of OL progenitors and myelination could be attributed to the dose and short duration $(10 \mathrm{~d})$ of the medication used in the study.

\section{Discussion}

IVH remains a major public health concern as both the incidence of prematurity and the survival of preterm infants have increased over the last 2 decades (Hamilton et al., 2007; Lau et al., 2013).
IVH results in hypomyelination of the white matter, manifesting as cerebral palsy and cognitive deficits in the survivors. At present, no preventive or therapeutic strategies exist for this disorder. Here we show that the development of IVH results in the coordinated upregulation of D3 and downregulation of D2 in the periventricular germinal matrix, setting the stage for a localized decrease in TH signaling. Additionally, enhanced TR $\alpha$ expression in a setting of reduced $\mathrm{T}_{3}$ levels increases the availability of unliganded TR that favorably associates with corepressor complexes, further decreasing local TH signaling. The significance of these findings is illustrated by the critical observation that $\mathrm{TH}$ treatment in preterm rabbits with IVH promotes the proliferation and maturation of OL progenitors, restores myelination, and enhances neurological recovery.

These findings are consistent with several recent studies reporting that cerebral insults, including hypoxia, trauma, and inflammation, alter the expression of D2 and D3 enzymes in neural cells (Zou et al., 1998; Lamirand et al., 2008; Jo et al., 2012). Specifically, hypoxia and hypoxia-inducible factors activate D3 enzymes in neurons and myocardium, thereby reducing $\mathrm{T}_{3}$ content in these cells (Simonides et al., 2008; Jo et al., 2012). In addition, coordinated changes in deiodinase expression are also seen in critically ill adults, thereby reducing the availability of TH (Peeters et al., 2003). The critical question is whether such a decrease in brain TH signaling in the 

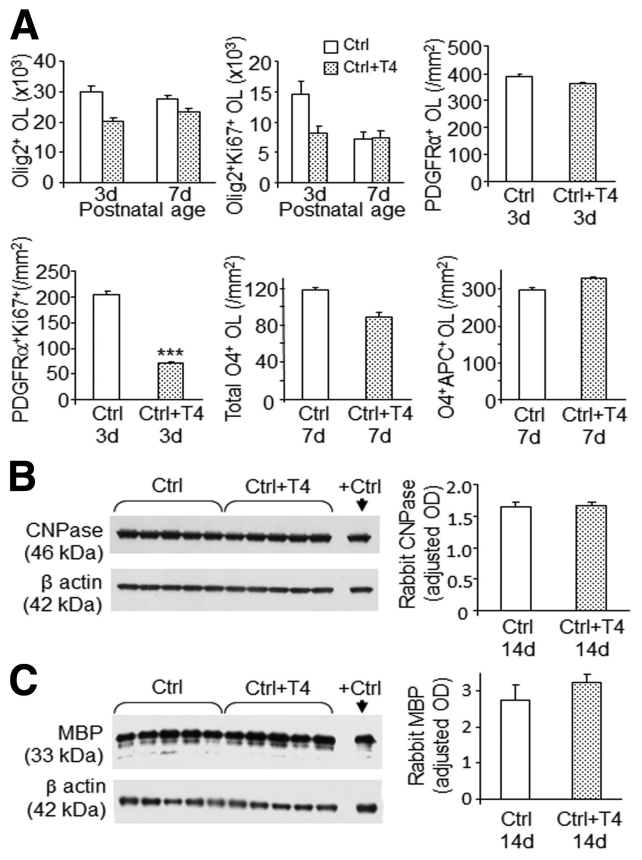

Figure 10. Thyroxine treatment reduces proliferation but does not affect the maturation of $0 \mathrm{Ls}$ or myelination in healthy rabbit pups. $A$, Coronal sections were stained using a combination of Olig2/Ki67, PDGFR $\alpha /$ Ki67, or 04/APC antibodies. Bar graphs show the mean \pm SEM ( $n=5$ each group). Total and cycling 0lig2 cells are similar in density between groups. However, proliferating PDGFR $\alpha^{+}$cells are reduced in thyroxine-treated pups compared with untreated controls. Densities of $04^{+}$and $04^{+} / \mathrm{APC}^{+}$cells are comparable between groups. $B, C$, Representative Western blot analyses for CNPase and MBP in forebrain homogenates of thyroxinetreated and untreated pups without IVH at $14 \mathrm{~d}$. Bar graphs show the mean \pm SEM ( $n=5$ each group). Protein concentration was normalized to $\beta$-actin. Adult rat brain was used as the positive control. No difference was seen between groups.

setting of IVH is adaptive or maladaptive, with the answer carrying major clinical significance as it could result in the recommendation for TH administration to infants with IVH.

An intriguing finding of the present study is the observation that $\mathrm{TH}$ administration restores myelination in a unique preterm rabbit model of glycerol-induced IVH. Similar to human preterm infants, premature rabbits exhibit a gyrencephalic brain, perinatal brain growth, abundant germinal matrix, and the capability of premature pups to survive. Moreover, IVH initiates in the germinal matrix in this model of IVH, just as in humans; and the animals with IVH develop hypomyelination at $14 \mathrm{~d}$ of age. Consistent with the findings of the present study, $\mathrm{TH}$ treatment improves myelination in adult models of both chronic inflammatory demyelinating disease and cuprizone-induced demyelination (Franco et al., 2008; D'Intino et al., 2011). Experimental allergic encephalomyelitis is an experimental model of multiple sclerosis, which exhibits demyelination areas in the brain and spinal cord. TH treatment in both adult rodents and monkeys (Callithrix jacchus) with chronic inflammatory demyelination leads to improvement in myelination (Franco et al., 2008; Harsan et al., 2008; D'Intino et al., 2011). Similarly, in a cuprizone model of toxic demyelination, which induces OL degeneration and disruption of the myelin sheath in rodents, TH treatment enhances remyelination by promoting differentiation of OL progenitors (Franco et al., 2008). Hence, TH treatment enhances myelination in our developmental model of IVH, just as in adult models of demyelination.

Our previous studies have shown that the development of IVH results in reduced proliferation, degeneration, and arrested maturation of OL progenitors in preterm rabbit pups (Dummula et al., 2011). In the present study, we demonstrated that TH treatment in rabbit pups with IVH induced (1) an elevation of cycling and total population of PDGFR $\alpha^{+},(2)$ increased density of proliferating and total Olig2 ${ }^{+}$cells, (3) a rise in the number of myelinating $\mathrm{OL}\left(\mathrm{O}_{4}^{+} \mathrm{APC}^{+}\right)$, and (4) an elevation in CNPase levels in thyroxine-treated pups relative to controls. An increase in the density of cycling and total PDGFR $\alpha^{+} \mathrm{OL}$ in thyroxine-treated pups suggests that thyroxine exposure promotes the specification and multiplication of undifferentiated OL progenitors. A rise in the density of $\mathrm{APC}^{+} \mathrm{OLs}$ and CNPase levels in thyroxine-treated pups relative to vehicle controls indicates the maturation of $\mathrm{OL}$ progenitors upon $\mathrm{TH}$ treatment. Consistent with our results, other reports have also shown that thyroxine treatment accelerates OL proliferation in adult rats (D'Intino et al., 2011). Moreover, a role of $\mathrm{TH}$ in enhancing the maturation of OLs has been demonstrated in animal models and culture experiments (Calza et al., 2002; Younes-Rapozo et al., 2006; Franco et al., 2008). Together, TH treatment promotes myelination by enhancing the population of both undifferentiated and differentiated OL progenitors.

The maturation of OLs is transcriptionally regulated, and basic helix-loop-helix (bHLH) transcription factors-Olig1, Olig2, Id2, Id4, and Sox10 - play key roles in OL lineage specification and in progressive stages of maturation leading to myelination (Stolt et al., 2002; Gokhan et al., 2005). The present study demonstrated that thyroxine treatment elevated Sox10 and Olig2 gene expression in pups with IVH, which are suppressed in rabbits after IVH. However, the other transcription factors (Olig1, Id2, and Id4) were not affected by thyroxine treatment. Since both Olig2 and Sox10 activate the MBP promoter, leading to terminal differentiation of OL progenitors, elevating these two transcription factors by thyroxine treatment would enhance myelination (Gokhan et al., 2005). In addition, Sox10 diverts multipotent neural progenitor cells toward the OL lineage during development (Pozniak et al., 2010). However, the amount of GFAP protein and mRNA, indicating astrocytes, did not change with thyroxine treatment. To our knowledge, the effect of TH on bHLH and high-mobility transcription factors have not been studied in any developmental models of hypomyelination or adult models of demyelination. Together, the present findings indicate that $\mathrm{TH}$ promotes $\mathrm{OL}$ progenitor maturation by increasing expression of Sox10 and Olig2 genes.

The availability of autopsy brain samples from premature infants with and without IVH was instrumental to determine the expression of deiodinases and TRs in these tissues. At the same time, we are cognizant of the inherent limitations of postmortem human samples with multiple confounding variables such as mechanical ventilation, exposure to a number of prenatal and postnatal medications, and others. More importantly, we evaluated the maturation of OLs in postmortem samples from preterm infants with IVH who were treated with TH in a double-blinded controlled trial, starting shortly after birth and continuing until their demise. Even though the sample size is limited to three in each group, the data obtained clearly indicate an increase in maturation of OL progenitors after $\mathrm{TH}$ treatment in human infants with IVH, suggesting that a TH clinical trial in infants with IVH to enhance myelination could be successful.

Excessive TH treatment is not without adverse effects and could potentially affect cardiovascular function, skeletal integrity, and others. In addition, prolonged treatment with high doses of TH increases OL apoptosis (Marta et al., 1998). Conversely, studies have shown that $\mathrm{TH}$ rescues developing OLs from death 
by apoptosis induced by proinflammatory cytokines (Jones et al., 2003). In the present study, TH supplementation did not affect active caspase 3 levels or the abundance of TUNEL ${ }^{+}$cells in pups with IVH. In addition, no apparent adverse effects of thyroxine treatment were noticed in this study. More importantly, thyroxine treatment in healthy controls did not alter the maturation of OL progenitors or myelination. Indeed, the safety of TH has been noted in a double-blinded randomized control trial for infants with and without IVH in doses of 4 or $8 \mu \mathrm{g} / \mathrm{kg} / \mathrm{d}$ (La Gamma et al., 2009).

IVH often results in cerebral palsy and cognitive deficits in premature infants, with neurologic sequelae present in $80-100 \%$ of the cases with moderate-to-severe IVH (Guzzetta et al., 1986; Bassan et al., 2006). At this time, there are no therapeutic or preventive strategies for infants with IVH. Based on quality-oflife concerns, active withdrawal of life support from premature infants with severe IVH, although infrequent, does occur (Sawyer, 2008). Hence, there is extreme need for a therapy to minimize white matter injury that follows IVH. Here, we have shown that TH treatment enhances OL progenitor maturation, myelination, and neurological outcome of preterm rabbit pups with IVH, without enhancing apoptosis in pups with IVH or in pups without IVH. Furthermore, the density of myelinating OLs $\left(\mathrm{O}_{4}^{+} \mathrm{O}^{-}\right)$was almost doubled in thyroxine-treated preterm infants. These findings set the stage for further testing the utility of $\mathrm{TH}$ in a phase II clinical trial in human neonates with moderateto-severe IVH.

\section{References}

Baas D, Bourbeau D, Sarliève LL, Ittel ME, Dussault JH, Puymirat J (1997) Oligodendrocyte maturation and progenitor cell proliferation are independently regulated by thyroid hormone. Glia 19:324-332. CrossRef Medline

Ballabh P, Xu H, Hu F, Braun A, Smith K, Rivera A, Lou N, Ungvari Z, Goldman SA, Csiszar A, Nedergaard M (2007) Angiogenic inhibition reduces germinal matrix hemorrhage. Nat Med 13:477-485. CrossRef Medline

Barca-Mayo O, Liao XH, Alonso M, Di Cosmo C, Hernandez A, Refetoff S, Weiss RE (2011) Thyroid hormone receptor alpha and regulation of type 3 deiodinase. Mol Endocrinol 25:575-583. CrossRef Medline

Bassan H, Benson CB, Limperopoulos C, Feldman HA, Ringer SA, Veracruz E, Stewart JE, Soul JS, Disalvo DN, Volpe JJ, du Plessis AJ (2006) Ultrasonographic features and severity scoring of periventricular hemorrhagic infarction in relation to risk factors and outcome. Pediatrics 117:21112118. CrossRef Medline

Bernal J (2007) Thyroid hormone receptors in brain development and function. Nat Clin Pract Endocrinol Metab 3:249-259. CrossRef Medline

Bystron I, Blakemore C, Rakic P (2008) Development of the human cerebral cortex: Boulder Committee revisited. Nat Rev Neurosci 9:110-122. CrossRef Medline

Calza L, Fernandez M, Giuliani A, Aloe L, Giardino L (2002) Thyroid hormone activates oligodendrocyte precursors and increases a myelinforming protein and NGF content in the spinal cord during experimental allergic encephalomyelitis. Proc Natl Acad Sci U S A 99:3258-3263. CrossRef Medline

Carré JL, Demerens C, Rodríguez-Peña A, Floch HH, Vincendon G, Sarliève LL (1998) Thyroid hormone receptor isoforms are sequentially expressed in oligodendrocyte lineage cells during rat cerebral development. J Neurosci Res 54:584-594. CrossRef Medline

Chua CO, Chahboune H, Braun A, Dummula K, Chua CE, Yu J, Ungvari Z, Sherbany AA, Hyder F, Ballabh P (2009) Consequences of intraventricular hemorrhage in a rabbit pup model. Stroke 40:3369-3377. CrossRef Medline

Courtin F, Zrouri H, Lamirand A, Li WW, Mercier G, Schumacher M, Goascogne CL, Pierre M (2005) Thyroid hormone deiodinases in the central and peripheral nervous system. Thyroid 15:931-942. CrossRef Medline

Curcio-Morelli C, Gereben B, Zavacki AM, Kim BW, Huang S, Harney JW, Larsen PR, Bianco AC (2003) In vivo dimerization of types 1, 2, and 3 iodothyronine selenodeiodinases. Endocrinology 144:937-946. CrossRef Medline

D’Intino G, Lorenzini L, Fernandez M, Taglioni A, Perretta G, Del Vecchio G, Villoslada P, Giardino L, Calzà L (2011) Triiodothyronine administration ameliorates the demyelination/remyelination ratio in a non-human primate model of multiple sclerosis by correcting tissue hypothyroidism. J Neuroendocrinol 23:778-790. CrossRef Medline

Dummula K, Vinukonda G, Chu P, Xing Y, Hu F, Mailk S, Csiszar A, Chua C, Mouton P, Kayton RJ, Brumberg JC, Bansal R, Ballabh P (2011) Bone morphogenetic protein inhibition promotes neurological recovery after intraventricular hemorrhage. J Neurosci 31:12068-12082. CrossRef Medline

Ercan-Fang S, Schwartz HL, Oppenheimer JH (1996) Isoform-specific 3,5,3'-triiodothyronine receptor binding capacity and messenger ribonucleic acid content in rat adenohypophysis: effect of thyroidal state and comparison with extrapituitary tissues. Endocrinology 137:3228-3233. CrossRef Medline

Fernandez M, Pirondi S, Manservigi M, Giardino L, Calzà L (2004a) Thyroid hormone participates in the regulation of neural stem cells and oligodendrocyte precursor cells in the central nervous system of adult rat. Eur J Neurosci 20:2059-2070. CrossRef Medline

Fernandez M, Giuliani A, Pirondi S, D’Intino G, Giardino L, Aloe L, LeviMontalcini R, Calzà L (2004b) Thyroid hormone administration enhances remyelination in chronic demyelinating inflammatory disease. Proc Natl Acad Sci U S A 101:16363-16368. CrossRef Medline

Franco PG, Silvestroff L, Soto EF, Pasquini JM (2008) Thyroid hormones promote differentiation of oligodendrocyte progenitor cells and improve remyelination after cuprizone-induced demyelination. Exp Neurol 212: 458-467. CrossRef Medline

Gereben B, Zavacki AM, Ribich S, Kim BW, Huang SA, Simonides WS, Zeöld A, Bianco AC (2008) Cellular and molecular basis of deiodinaseregulated thyroid hormone signaling. Endocr Rev 29:898-938. CrossRef Medline

Giardino L, Bettelli C, Calzà L (2000) In vivo regulation of precursor cells in the subventricular zone of adult rat brain by thyroid hormone and retinoids. Neurosci Lett 295:17-20. CrossRef Medline

Gokhan S, Marin-Husstege M, Yung SY, Fontanez D, Casaccia-Bonnefil P, Mehler MF (2005) Combinatorial profiles of oligodendrocyte-selective classes of transcriptional regulators differentially modulate myelin basic protein gene expression. J Neurosci 25:8311-8321. CrossRef Medline

Grommen SV, Arckens L, Theuwissen T, Darras VM, De Groef B (2008) Thyroid hormone receptor beta2 is strongly up-regulated at all levels of the hypothalamo-pituitary-thyroidal axis during late embryogenesis in chicken. J Endocrinol 196:519-528. CrossRef Medline

Guzzetta F, Shackelford GD, Volpe S, Perlman JM, Volpe JJ (1986) Periventricular intraparenchymal echodensities in the premature newborn: critical determinant of neurologic outcome. Pediatrics 78:995-1006. Medline

Hamilton BE, Miniño AM, Martin JA, Kochanek KD, Strobino DM, Guyer B (2007) Annual summary of vital statistics: 2005. Pediatrics 119:345-360. CrossRef Medline

Harsan LA, Steibel J, Zaremba A, Agin A, Sapin R, Poulet P, Guignard B, Parizel N, Grucker D, Boehm N, Miller RH, Ghandour MS (2008) Recovery from chronic demyelination by thyroid hormone therapy: myelinogenesis induction and assessment by diffusion tensor magnetic resonance imaging. J Neurosci 28:14189-14201. CrossRef Medline

Horn S, Heuer H (2010) Thyroid hormone action during brain development: more questions than answers. Mol Cell Endocrinol 315:19-26. CrossRef Medline

Huang SA, Mulcahey MA, Crescenzi A, Chung M, Kim BW, Barnes C, Kuijt W, Turano H, Harney J, Larsen PR (2005) Transforming growth factorbeta promotes inactivation of extracellular thyroid hormones via transcriptional stimulation of type 3 iodothyronine deiodinase. Mol Endocrinol 19:3126-3136. CrossRef Medline

Jo S, Kalló I, Bardóczi Z, Arrojo e Drigo R, Zeöld A, Liposits Z, Oliva A, Lemmon VP, Bixby JL, Gereben B, Bianco AC (2012) Neuronal hypoxia induces Hsp40-mediated nuclear import of type 3 deiodinase as an adaptive mechanism to reduce cellular metabolism. J Neurosci 32:8491-8500. CrossRef Medline

Jones SA, Jolson DM, Cuta KK, Mariash CN, Anderson GW (2003) Triiodothyronine is a survival factor for developing oligodendrocytes. Mol Cell Endocrinol 199:49-60. CrossRef Medline

Kanamori A, Brown DD (1992) The regulation of thyroid hormone recep- 
tor beta genes by thyroid hormone in Xenopus laevis. J Biol Chem 267: 739-745. Medline

La Gamma EF, van Wassenaer AG, Ares S, Golombek SG, Kok JH, Quero J, Hong T, Rahbar MH, de Escobar GM, Fisher DA, Paneth N (2009) Phase 1 trial of 4 thyroid hormone regimens for transient hypothyroxinemia in neonates of $<28$ weeks' gestation. Pediatrics 124:e258-e268. CrossRef Medline

Lamirand A, Pallud-Mothré S, Ramaugé M, Pierre M, Courtin F (2008) Oxidative stress regulates type 3 deiodinase and type 2 deiodinase in cultured rat astrocytes. Endocrinology 149:3713-3721. CrossRef Medline

Lau C, Ambalavanan N, Chakraborty H, Wingate MS, Carlo WA (2013) Extremely low birth weight and infant mortality rates in the United States. Pediatrics 131:855-860. CrossRef Medline

Margaill I, Royer J, Lerouet D, Ramaugé M, Le Goascogne C, Li WW, Plotkine M, Pierre M, Courtin F (2005) Induction of type 2 iodothyronine deiodinase in astrocytes after transient focal cerebral ischemia in the rat. J Cereb Blood Flow Metab 25:468-476. CrossRef Medline

Marta CB, Adamo AM, Soto EF, Pasquini JM (1998) Sustained neonatal hyperthyroidism in the rat affects myelination in the central nervous system. J Neurosci Res 53:251-259. CrossRef Medline

Mouton PR, Chachich ME, Quigley C, Spangler E, Ingram DK (2009) Caloric restriction attenuates amyloid deposition in middle-aged dtg APP/ PS1 mice. Neurosci Lett 464:184-187. CrossRef Medline

Nicolay DJ, Doucette JR, Nazarali AJ (2007) Transcriptional control of oligodendrogenesis. Glia 55:1287-1299. CrossRef Medline

Peeters RP, Wouters PJ, Kaptein E, van Toor H, Visser TJ, Van den Berghe G (2003) Reduced activation and increased inactivation of thyroid hormone in tissues of critically ill patients. J Clin Endocrinol Metab 88:32023211. CrossRef Medline

Pozniak CD, Langseth AJ, Dijkgraaf GJ, Choe Y, Werb Z, Pleasure SJ (2010) Sox10 directs neural stem cells toward the oligodendrocyte lineage by decreasing suppressor of fused expression. Proc Natl Acad Sci U S A 107: 21795-21800. CrossRef Medline

Rodríguez-Peña A (1999) Oligodendrocyte development and thyroid hormone. J Neurobiol 40:497-512. CrossRef Medline
Royer C, Lachuer J, Crouzoulon G, Roux J, Peyronnet J, Mamet J, Pequignot J, Dalmaz Y (2000) Effects of gestational hypoxia on mRNA levels of Glut3 and Glut4 transporters, hypoxia inducible factor-1 and thyroid hormone receptors in developing rat brain. Brain Res 856:119-128. CrossRef Medline

Sarliève LL, Rodríguez-Peña A, Langley K (2004) Expression of thyroid hormone receptor isoforms in the oligodendrocyte lineage. Neurochem Res 29:903-922. CrossRef Medline

Sawyer T (2008) Withdrawing support for withdrawing support from premature infants with severe intracranial hemorrhage. Pediatrics 121:10711072. CrossRef Medline

Sharlin DS, Tighe D, Gilbert ME, Zoeller RT (2008) The balance between oligodendrocyte and astrocyte production in major white matter tracts is linearly related to serum total thyroxine. Endocrinology 149:2527-2536. CrossRef Medline

Simonides WS, Mulcahey MA, Redout EM, Muller A, Zuidwijk MJ, Visser TJ, Wassen FW, Crescenzi A, da-Silva WS, Harney J, Engel FB, Obregon MJ, Larsen PR, Bianco AC, Huang SA (2008) Hypoxia-inducible factor induces local thyroid hormone inactivation during hypoxic-ischemic disease in rats. J Clin Invest 118:975-983. CrossRef Medline

Stolt CC, Rehberg S, Ader M, Lommes P, Riethmacher D, Schachner M, Bartsch U, Wegner M (2002) Terminal differentiation of myelinforming oligodendrocytes depends on the transcription factor Sox10. Genes Dev 16:165-170. CrossRef Medline

Younes-Rapozo V, Berendonk J, Savignon T, Manhães AC, Barradas PC (2006) Thyroid hormone deficiency changes the distribution of oligodendrocyte/myelin markers during oligodendroglial differentiation in vitro. Int J Dev Neurosci 24:445-453. CrossRef Medline

Zhu Z, Zhao B, Wang X, Zhu S, Zhang Q, Xu Y, Hui R, Tepel M (2004) Differentially expressed genes in hypertensive rats developing cerebral ischemia. Life Sci 74:1899-1909. CrossRef Medline

Zou L, Burmeister LA, Styren SD, Kochanek PM, DeKosky ST (1998) Up-regulation of type 2 iodothyronine deiodinase mRNA in reactive astrocytes following traumatic brain injury in the rat. J Neurochem 71:887890. Medline 